\title{
Molecular Biology-Based Analysis of the Interactive Effect of Nickel and Xanthates on Soil Bacterial Community Diversity and Structure
}

\author{
Prudence Bararunyeretse ${ }^{1,2, *}$, Yan Zhang ${ }^{1}$ and Hongbing $\mathrm{Ji}^{1, *(1)}$ \\ 1 Beijing Key Laboratory of Resource-oriented Treatment of Industrial Pollution, School of Energy and \\ Environmental Engineering, University of Science and Technology Beijing, 30 Xueyuan Road, \\ Beijing 100083, China \\ 2 Biology Department, Faculty of Sciences, University of Burundi, Bujumbura 1550, Burundi \\ * Correspondence: prudencebara@gmail.com (P.B.); ji.hongbing@hotmail.com (H.J.)
}

Received: 20 May 2019; Accepted: 24 June 2019; Published: 17 July 2019

\begin{abstract}
Metals and mineral flotation collector's toxicity to the soil living system greatly compromise the sustainability of mining and ore processing. Their effects on the soil microbial community, the most active soil component, remain less understood and addressed particularly with regards to xanthates and their combination with metals. This study analyzed the interactive effects of $\mathrm{Ni}$ and xanthates, potassium ethyl xanthate and sodium isopropyl xanthate, on the soil bacterial community through an efficient molecular biology-based technique, the Miseq (Illumina). Both soil microbial community diversity and structure were more affected by xanthates than by Ni. The five most dominant phyla, representing $96.31 \%$ of the whole bacterial community, comprised Proteobacteria $(54.16 \%)$, Firmicutes (17.51\%), Actinobacteria (15.59\%), Acidobacteria (4.87\%), and Chloroflexi $(4.16 \%)$. Different soil treatments exhibited greater difference in the species abundance/dominance than in the species numbers. Proteobacteria was the most dominant in the presence of xanthates, individually or in mixtures with nickel, while Firmicutes exhibited its highest proportion in the Ni/xanthate-treated samples. The most abundant and proportionally different bacterial species between different treatments were presented. The most abundant bacterial strains identified should be explored more for their potential application in biomining and for the prediction and biologically-based treatment and remediation of $\mathrm{Ni}$ and xanthate-contaminated systems.
\end{abstract}

Keywords: mining; xanthates; nickel; soil bacteria; interactive effect; molecular technique

\section{Introduction}

Wastes discharged from mining and ore processing contain various pollutants, including heavy metals (e.g., nickel) and flotation reagents (e.g., xanthates). The associated soil contamination has become of great ecological and health concern [1], compromising the sustainability of these activities. Soil microorganisms could be the most affected organisms as they constitute the most active soil component [2], which mediates about $80-90 \%$ of the various biochemical processes within the soil [2,3], including soil formation and aggregation [3,4], soil decontamination, detoxification and restoration [1], soil organic matter decomposition, soil nutrient cycling, etc. [5].

In addition to Ni mining and processing which are the main anthropogenic sources of Ni pollution, $\mathrm{Ni}$ is released into the environment from various anthropogenic sources, including transportation, oil combustion, and municipal and industrial wastes [6]. High Ni concentrations in the soil, more than $300 \mu \mathrm{g} \cdot \mathrm{g}^{-1}$ soil [6-8], were reported in the soils from various sites, including rural areas of various countries. This is well above the permissible limit (less than $50 \mu \mathrm{g}^{-1} \mathrm{~g}^{-1}$ soil for agricultural and 
non-industrialized soil and less than $100 \mu \mathrm{g} \cdot \mathrm{g}^{-1}$ soil for commercial and industrial lands) [9]. On the other hand, the mining industry relies heavily on the use of flotation reagents to extract valuable minerals from the rest of the gangue by flotation [10].

Xanthates $\left(\mathrm{ROCS}_{2}{ }^{-} \mathrm{Na}^{+} / \mathrm{K}^{+}\right)$are man-made organic chemicals that not only have high mineral selectivity, but are also cost-effective and are the compounds commonly used as sulfide minerals' flotation collectors [11]. Sodium isopropyl xanthate (SIPX) and potassium ethyl xanthate (PEX) are the most frequently used for $\mathrm{Ni}$ flotation and recovery. Of the input reagents' quantity, $10 \mathrm{~g}$ to more than $400 \mathrm{~g} /$ ton ore [10], only half is effectively consumed during the flotation [11]. The remaining part and the unrecovered metals are discharged into the environment, with no treatment in general [12]. In addition, the reported increase in $\mathrm{Ni}$ demand [6] and the gradual depletion of high-grade ore reserves leads to the exploitation of complex and low-grade ore [13]. This results in an increased amount of ore processed and xanthates consumed, by 2-3\% per year [12], leading to higher $\mathrm{Ni}$ and xanthates released into the environment. Xanthates are also released into the environment from their use in the agriculture sector (e.g., pesticides), rubber sector (i.e., vulcanizing agents), and in metallurgy, etc., and can reach the soil from their manufacturing, transportation (e.g., accidental spills), and improper disposal [14]. Both $\mathrm{Ni}$ and xanthates are also spread into the environment from mine tailings [15], the main mining waste dumping sites, from which they are dispersed to surface and ground waters by leaching and infiltration and can also reach long distances by wind, run-off and erosion, plant uptake [1], and transfer via the food web [16].

Toxicologically, Ni was reported as an allergenic and carcinogenic metal that can damage various tissues, organs, and systems in humans [17-20]. Excessive soil Ni concentration also has deleterious effects on plants $[8,21]$. Regarding xanthates, human and animal exposure leads to multisided effects (e.g., oral and dermal acute toxicity, damage of the eye, liver, kidneys, spleen, and respiratory and nervous systems [14]. Xanthates were reported as tremendously toxic to aquatic organisms, with a high sensitivity to less than $1 \mathrm{mg} / \mathrm{L}$ [22].

To survive under the above described adverse conditions, some microbes have developed tolerance and resistance abilities. The identification and application of such specific microbial strains could serve for the remediation of $\mathrm{Ni}$ and xanthate-associated pollution. However, $\mathrm{Ni}$ [23] and more particularly xanthate- related studies [14] are still scarce. Moreover, pollution and health risk assessment studies have mostly focused on single substances while the exposure to multiple chemical agents can result in either additive actions, synergistic interactions or antagonistic interactions [24]. Metals, being most toxic in their free ionic forms (e.g., $\mathrm{Ni}^{2+}$ ), also combine with xanthates, the interaction between $\mathrm{Ni}$ and xanthates becoming toxicologically relevant. Exposure to structurally and ecologically different chemicals is of great technological and pharmaceutical interest $[25,26]$. Analyzing the response of soil microorganisms to metals and flotation reagents, individually and as mixtures, can serve for a greater understanding of the associated pollution impacts and for their prediction and management. The majority of studies have focused on the application of different traditional techniques at the community level $[27,28]$ which cannot provide enough information on the spectrum of taxa in the exposed microbial community [28]. Previous to the present study, a microcalorimetric-based analysis was conducted to analyze the individual and interactive effect chemicals used here on the soil microbial activity [29]. The obtained results have raised great scientific interest. However, the limitation of the study was the lack of information on which microbes are the most affected and those that are less sensitive or adapted to the applied pollutants and are, thus, most responsible for the observed activity level. The analyses based on the molecular biology approach used here are the best way to overcome this limitation [30]. The sequencing and analysis of the $16 \mathrm{~S}$ ribosomal RNA (rRNA) genes in prokaryotes is one of the most useful advanced techniques for the characterization of the bacterial community [31,32].

Two main hypotheses led to conducting the present study. Firstly, the affinity between metals and their respective flotation collectors can affect the bioavailability of both chemicals and their interaction with the exposed organisms. Secondly, different soil microbial strains may variably respond to $\mathrm{Ni}$ 
and xanthates, individually and in the mixtures. Accordingly, this study analyzed the toxicity of single and combined $\mathrm{Ni}\left(\mathrm{NiCl}_{2} \cdot 6 \mathrm{H}_{2} \mathrm{O}\right)$ and xanthates, $\mathrm{SIPX}\left(\mathrm{C}_{3} \mathrm{H}_{7} \mathrm{OCS}_{2} \mathrm{Na}\right)$ and PEX $\left(\mathrm{C}_{2} \mathrm{H}_{5} \mathrm{OCS}_{2} \mathrm{~K}\right)$, on the bacterial community diversity and structure. The analysis included direct soil DNA extraction, $16 \mathrm{~S}$ rRNA amplification, Illumina high-throughput sequencing, and related data analysis. The study has a two-fold advantage: (1) To provide basic information on the effect of the studied chemicals on soil bacterial community and (2) to give an insight of the sensitivity of different soil bacterial species to the studied chemicals that will enable better identification and analysis of the resistance capability of specific bacterial strains.

\section{Material and Methods}

\subsection{Sample Preparation}

The study was conducted on duplicated soil samples collected from Beijing $\left(39^{\circ} 59^{\prime} \mathrm{N}, 116^{\circ} 21^{\prime} \mathrm{E}\right)$ in July 2017. The uppermost surface soil layer was removed and soil samples were obtained from the 5-15 cm soil layer, the most heavily populated soil section by microorganisms [33]. Large particles, such as plant roots and plant debris, grit, and earthworms, were removed and then soils were placed in sterile polyethylene bags and transported to the laboratory. They were then air-dried at room temperature, homogenized, sieved ( $2 \mathrm{~mm}$ mesh), and kept at $4{ }^{\circ} \mathrm{C}$ before use. A pH meter (Beckmanu 690 ) was used to determine the $\mathrm{pH}$ of the soil. The measurement of the soil organic matter (OM) was processed through an outer heating method by potassium dichromate oxidation based on GB7857-87 (2002). The nitrogen $(\mathrm{N})$ content was evaluated by element analyzer (VARIO EL3, Germany). Potassium (K) content and soluble phosphate $(\mathrm{P})$ content were determined by extracting a percolated fraction of $5.0 \mathrm{~g}$ of soil with $50.0 \mathrm{~mL}$ solution comprised of $0.2 \mathrm{~mol} \cdot \mathrm{L}^{-1}$ ethanoic acid $\left(\mathrm{CH}_{3} \mathrm{COOH}\right), 0.25 \mathrm{~mol} \cdot \mathrm{L}^{-1}$ ammonium nitrate $\left(\mathrm{NH}_{4} \mathrm{NO}_{3}\right), 0.015 \mathrm{~mol} \cdot \mathrm{L}^{-1}$ ammonium fluoride $\left(\mathrm{NH}_{4} \mathrm{~F}\right), 0.013 \mathrm{~mol} \cdot \mathrm{L}^{-1}\left(\mathrm{HNO}_{3}\right)$, and $0.001 \mathrm{~mol} \cdot \mathrm{L}^{-1}$ ethylene diamine tetraacetic acid (EDTA), $\left.\mathrm{pH}=2.5\right)$. Flame photometry and photometry allowed determining the $\mathrm{K}$ and $\mathrm{P}$, respectively. The following were the obtained values: soil $\mathrm{pH} 7.28 ; 17.21 \mathrm{~g} \mathrm{OM} \cdot \mathrm{kg}^{-1}$ soil, $75.8 \mathrm{mg} \mathrm{N} \cdot \mathrm{kg}^{-1}$ soil, $78.1 \mathrm{mg} \mathrm{P} \cdot \mathrm{kg}^{-1}$ soil, and $145.3 \mathrm{mg} \mathrm{K} \cdot \mathrm{kg}^{-1}$ soil.

Xanthates, PEX and SIPX, were obtained in solid and analytical grade from the Beijing General Research Institute of Mining and Metallurgy (Beijing, China). Distilled water was used to make chemical stock solutions. As done in previous studies [29,34-36], each sample was supplemented with a $200 \mathrm{~mL}$ nutrient solution made of glucose $(500 \mathrm{mg})$ and ammonium sulfate $(500 \mathrm{mg})$ in a 1:1 proportion. The latter has demonstrated its efficacy in providing nitrogen and sulfur that are needed for the amino acids' microbial synthesis and in stimulating microbial growth and activity $[37,38]$. At the same time, except for the control sample which consisted of a non-amended sample, the soil samples were spiked with either a single dose of $\mathrm{Ni}\left(300 \mu \mathrm{g} \cdot \mathrm{g}^{-1}\right.$ soil), SIPX and PEX (50 and $100 \mu \mathrm{g} \cdot \mathrm{g}^{-1}$ soil), or a mixture dose of $\mathrm{Ni}\left(300 \mu \mathrm{g} \cdot \mathrm{g}^{-1}\right.$ soil) and xanthates (50 or $100 \mu \mathrm{g} \cdot \mathrm{g}^{-1}$ soil) (Table 1). Prior to DNA extraction, soil samples were incubated for a period time of six days at $36^{\circ} \mathrm{C}$.

Table 1. Pollutant concentration for each treatment.

\begin{tabular}{ccccccccccc}
\hline & $\begin{array}{c}\text { Control } \\
\text { Sample }\end{array}$ & \multicolumn{4}{c}{ Single Chemical Treatments } & & \multicolumn{3}{c}{ Mixed-Chemical Treatments (Ni + Xanthates) } \\
\cline { 5 - 11 } & & & & & & & \multicolumn{2}{c}{ Ni + PEX } & \multicolumn{2}{c}{ Ni + SIPX } \\
\hline Samples Code & CS & Ni & PEXa & PEXb & SIPXa & SIPXb & M1a & M1b & M2a & M2b \\
\hline Dose $\left(\mu \mathrm{g} \cdot \mathrm{g}^{-1}\right.$ soil $)$ & 0 & 300 & 50 & 100 & 50 & 100 & $300+50$ & $300+100$ & $300+50$ & $300+100$ \\
\hline
\end{tabular}

$\mathrm{CS}=$ Control sample; $\mathrm{Ni}=$ Nickel; $\mathrm{PEX}=$ potassium ethyl xanthate; $\mathrm{SIPX}=$ sodium isopropyl xanthate; $\mathrm{M}=$ Mixture $(\mathrm{M} 1 \mathrm{a}=\mathrm{Ni}+\mathrm{PEXa}, \mathrm{M} 1 \mathrm{~b}=\mathrm{Ni}+\mathrm{PEXb}, \mathrm{M} 2 \mathrm{a}=\mathrm{Ni}+\mathrm{SIPX} \mathrm{a}$, and M2b $=\mathrm{Ni}+\mathrm{SIPXb})$.

\subsection{DNA Extraction and PCR Amplification}

Soil DNA extraction and PCR amplification were performed as recently processed [39,40]. Total soil DNA was successfully extracted using the E.Z.N.A. ${ }^{\circledR}$ Soil DNA Kit (Omega Bio-Tek, Norcross, GA, USA) and protocol. The concentration and purification of the final DNA were assessed spectrophotometrically 
using a NanoDrop 2000 UV-VIS spectrophotometer (Thermo Scientific, Wilmington, NC, USA) following the instructions of the Majorbio Bio-Pharm Technology Co. Ltd. (Shanghai, China) and as recently done in other similar studies [40-42]. The agarose gel (1\%) electrophoresis was used to determine the quality of DNA extracts. Further, polymerase chain reaction (PCR) amplification of the V3-V4 hypervariable regions of the $16 \mathrm{~S}$ ribosomal ribonucleic acid (16S rRNA) genes was performed using a GeneAmp 9700 thermocycler PCR system (Applied Biosystems, 850 Lincoln Centre Drive, Foster City, CA 94404, USA) with primers 338F (5'-ACTCCTACGGGAGGCAGCAG-3') and 806R (5'-GGACTACHVGGGTWTCTAAT-3'). 5-7 bp barcodes were added during the process. Then, adapters were added to the amplification products by deoxyribonucleic acid ligase following the protocol from Illumina (San Diego, CA, USA). The amplification was processed as follows: (1) an initial denaturation at $95^{\circ} \mathrm{C}(3 \mathrm{~min})$ followed by a final denaturation by 27 cycles at $95{ }^{\circ} \mathrm{C}(30 \mathrm{~s})$; (2) annealing at $55^{\circ} \mathrm{C}(30 \mathrm{~s}) ;(3)$ elongation at $72{ }^{\circ} \mathrm{C}(45 \mathrm{~s})$, and (4) final extension at $72{ }^{\circ} \mathrm{C}(10 \mathrm{~min})$ [43]. Negative controls without DNA were run in all amplifications. Reactions were conducted in a triplicate $20 \mu \mathrm{L}$ mixture made of $4 \mu \mathrm{L}$ of $5 \times$ FastPfu Buffer, $2 \mu \mathrm{L}$ of $2.5 \mathrm{mM}$ deoxyribonucleoside triphosphate (dNTPs), $0.8 \mu \mathrm{L}$ of each primer $(5 \mu \mathrm{M}), 0.4 \mu \mathrm{L}$ of FastPfu Polymerase, and $10 \mathrm{ng}$ of template DNA [44]. PCR products were extracted from a $2 \%$ agarose gel then purified using the AxyPrep DNA Gel Extraction Kit (Axygen Biosciences, Union City, CA, USA), followed by quantification using the QuantiFluor ${ }^{\mathrm{TM}}-\mathrm{ST}$ (Promega, Madison, WI, USA), as recommended by the manufacturer [40].

\subsection{Illumina Sequencing and Data Processing}

The purified amplicons were effectively pooled in equimolar ratio to build the sequencing library and paired-end sequenced $(2 \times 300)$ on a MiSeq (Illumina) platform, following the standard protocol of Majorbio Bio-Pharm Technology Co. Ltd. (Shanghai, China) [40]. The raw reads were deposited into the NCBI Sequence Read Archive (SRA) database (accession number: PRJNA514197).

After being demultiplexed, raw fastq files were quality-filtered by trimmomatic and were merged by fast length adjustment of short reads, FLASH, as follows: (1) reads were all truncated at sites with an average quality score of 20 or less over a $50 \mathrm{bp}$ sliding window; (2) primers were matched for nucleotides mismatching, and all reads with ambiguous bases were detached; (3) sequences with more than $10 \mathrm{bp}$ overlap were merged based on the overlap sequence. Operational taxonomic units (OTUs) (sequences that have 97\% similarity) were clustered with 3\% dissimilarity cut-off using the UPARSE algorithm (version 7.1) [28]. To obtain high-quality OTU sequences [45], all chimeric sequences were detected and removed using UCHIME [44]. As it was done for the DNA extraction and PCR amplification, the gene sequencing and data processing were performed with the technical assistance of the laboratory team of the Majorbio Bio-Pharm Technology Co. Ltd.

As previously done in other similar studies [39,40], data analysis was performed using the i-Sanger platform (http://www.i-sanger.com/) of the Majorbio Bio-PharmTechnology Co. Ltd. (Shanghai, China) and using the rarefied data. The microbial community alpha diversity was estimated through the following different indices, calculated by the Mothur program (version v.1.30.1 [46]. The community richness was evaluated using Chao1 and Ace estimators. Shannon diversity index and the abundance-based coverage estimator (refers to the coverage rate of each sample library) were calculated to estimate the community diversity [28]. Venn diagram analysis, using $\mathrm{R}$ language tools statistics and mapping [47] allowed evaluating the similarities and differences between samples based on the number of shared and unique OTUs [40]. To obtain the species classification information corresponding to each OTU sequence, the taxonomic analysis was performed using the Ribosomal Database Project (RDP) Classifier Bayesian algorithm [48] against the Silva (SSU128) 16S rRNA database at a confidence threshold of 70\% [49]. Bacterial community composition and species abundance analysis at different taxonomic levels (e.g., phylum, class, family, genus, and species) and principal coordinate analysis (PCoA) was performed based on the Bray-Curtis distance algorithm. A comparison between samples was made based on the relative taxa or species abundance/dominance. For the statistical analysis, samples treated with the same dose of xanthates were grouped together (no remarkable 
difference was observed between the same dose of PEX and SIPX). This made four replicates for each category of the compared treatments (single xanthate-treated samples and their corresponding $\mathrm{Ni} /$ xanthate-treated samples). The xanthate-treated samples were compared to their corresponding mixture treatments by grouping together the samples treated with the same dose of PEX and SIPX, individually and in the mixtures. Student's $t$-test, at a 95\% significance level, was performed for this comparison. The most proportionally different bacterial species between these two types of sample treatments were presented.

\section{Results and Discussion}

\subsection{Bacterial Community Richness and Diversity}

Of the total number of 918,762 high-quality sequences, 682,554 16S rRNA effective gene sequence reads were obtained across all samples (Table 2).

Table 2. Bacterial community alpha diversity indices and the $t$-test between xanthate-treated samples and their corresponding mixtures-treated samples. See Table 1 for sample codes. Compared samples exhibited more/significant differences $(p \leq 0.05)$ between indices in the case of a xanthate dose of $50 \mu \mathrm{g} \mathrm{g}^{-1}$ soil $(\mathrm{Xa} / \mathrm{Ma})$ than in the case of $100 \mu \mathrm{g} \cdot \mathrm{g}^{-1}$ soil $(\mathrm{Xb} / \mathrm{Mb})$.

\begin{tabular}{|c|c|c|c|c|c|c|c|c|c|c|c|}
\hline \multirow{5}{*}{$\begin{array}{l}\text { Alpha } \\
\text { diversity } \\
\text { indices }\end{array}$} & Estimators & CS & $\mathrm{Ni}$ & PEXa & PEXb & SIPXa & SIPXb & M1a & M1b & M2a & M2b \\
\hline & Simpson & 0.01 & 0.03 & 0.03 & 0.09 & 0.04 & 0.04 & 0.08 & 0.13 & 0.17 & 0.05 \\
\hline & Chao1 & 2112.16 & 2151.69 & 2069.33 & 1980.78 & 2074.68 & 2015.50 & 1946.31 & 2027.02 & 1869.38 & 2064.57 \\
\hline & Coverage & 0.995 & 0.996 & 0.995 & 0.994 & 0.994 & 0.995 & 0.995 & 0.995 & 0.994 & 0.996 \\
\hline & OTUs & 1899 & 1997 & 1888 & 1727 & 1812 & 1789 & 1621 & 1787 & 1447 & 1892 \\
\hline \multirow{5}{*}{$\begin{array}{c}t \text {-test } \\
\text { between } \\
\text { indices }\end{array}$} & Estimators & Ma-Mean & Ma-Sd & Xa-Mean & Xa-Sd & $p$-Value & Mb-Mean & Mb-Sd & Xb-Mean & $\mathrm{Xb}-\mathrm{Sd}$ & $p$-Value \\
\hline & Ace & 1906.6 & 42.825 & 2071.5 & 2.7211 & 0.03223 & 2033.8 & 11.075 & 1991.2 & 23.742 & 0.1485 \\
\hline & Chao & 1907.8 & 54.402 & 2072 & 3.7884 & 0.05099 & 2045.8 & 26.55 & 1998.1 & 24.553 & 0.2034 \\
\hline & Coverage & 0.99479 & 0.0005 & 0.99499 & 0.0007 & 0.7837 & 0.9955 & 0.0006 & 0.99439 & 0.0005 & 0.1576 \\
\hline & Shannon & 3.3431 & 0.5042 & 5.0045 & 0.1302 & 0.04577 & 4.3906 & 0.5928 & 4.5402 & 0.3035 & 0.7808 \\
\hline
\end{tabular}

Sd = standard deviation.

The sequence length averaged at $443 \mathrm{bp}$, with $70.9 \%$ ranging between of $441-460 \mathrm{bp}$, the remaining part $(29.1 \%)$ ranging between 421 and $440 \mathrm{bp}$. The microbial community richness and diversity index values, and the population size at different taxonomic level (phylum, family, genus, and species), are presented in Table 2 . All samples reached $98 \%$ of the coverage, demonstrating a high-sequence detection level [40].

The above-mentioned microcalorimetrically-based analysis of the total microbial activity revealed a higher inhibition rate of the microbial activity by xanthates than by nickel (e.g., $\mathrm{IC}_{50}$ (concentration that can inhibit $50 \%$ of the microbial activity) of $438.69 \mu \mathrm{g} \cdot \mathrm{g}^{-1}, 225.76 \mu \mathrm{g} \cdot \mathrm{g}^{-1}$, and $39.65 \mu \mathrm{g}$ per gram of soil for Ni, SIPX, and PEX, respectively [29]). In the present study, the control sample exhibited the highest bacterial community diversity (Shannon index value equal to 5.78). The variations observed in the bacterial diversity index values (Table 2) are in line with the rank-abundance curves (Figure 1) which reflected lower bacterial community diversity in the $\mathrm{Ni} /$ xanthate-treated samples than in their corresponding single chemicals. Ni exhibited the highest diversity index than all other polluted samples. Thus, xanthates were more adverse than Ni. The following reasons could be among those that can explain the observed higher microbial diversity in the nickel-polluted soil than in the xanthate-polluted soil: (1) The natural occurrence and large distribution of $\mathrm{Ni}$ in the environment, ranking 24th most abundant (twice as abundant as copper) in the lithosphere [8], and the subsequent long evolution of the soil microbes in its presence could have led to their development of structural and physiological adaptive mechanisms [50] to the stress induced by this non-organic 
element [51]. Ni-containing proteins were reported as a part of Ni homeostatic mechanisms within the soil microorganisms [52]. In contrast, xanthates, which are man-made organic chemicals, were firstly produced in the early 1900s. They are essentially used for mineral flotation from which they are mainly released into the environment [10-12]. Therefore, microbial resistance mechanisms to xanthates may still relatively lower than that for metals. (2) $\mathrm{Ni}$ is a micronutrient, essentially involved in the metabolism of nitrogen, hydrogen, and other physiologically important elements. It is involved as a component or cofactor of several metalloenzymes, including acireductone dioxygenase, $\mathrm{Ni}$-superoxide dismutase, methyl coenzyme $\mathrm{M}$ reductase, acetyl-CoA synthetase/decarboxylase, carbon monoxide dehydrogenase, and urease $[6,51,53]$. However, above a certain concentration limit, metals become deleterious, with different toxic mechanisms, including inhibiting cell division, enzyme activity and transcription, denaturing proteins, disrupting the cell membrane [8,54], etc., which result in the reduction of the diversity and size of a given exposed microbial population. Similarly, xanthates may severely interact with the exposed organisms, resulting in their relatively high toxicity which is perceived at both cellular and community level.

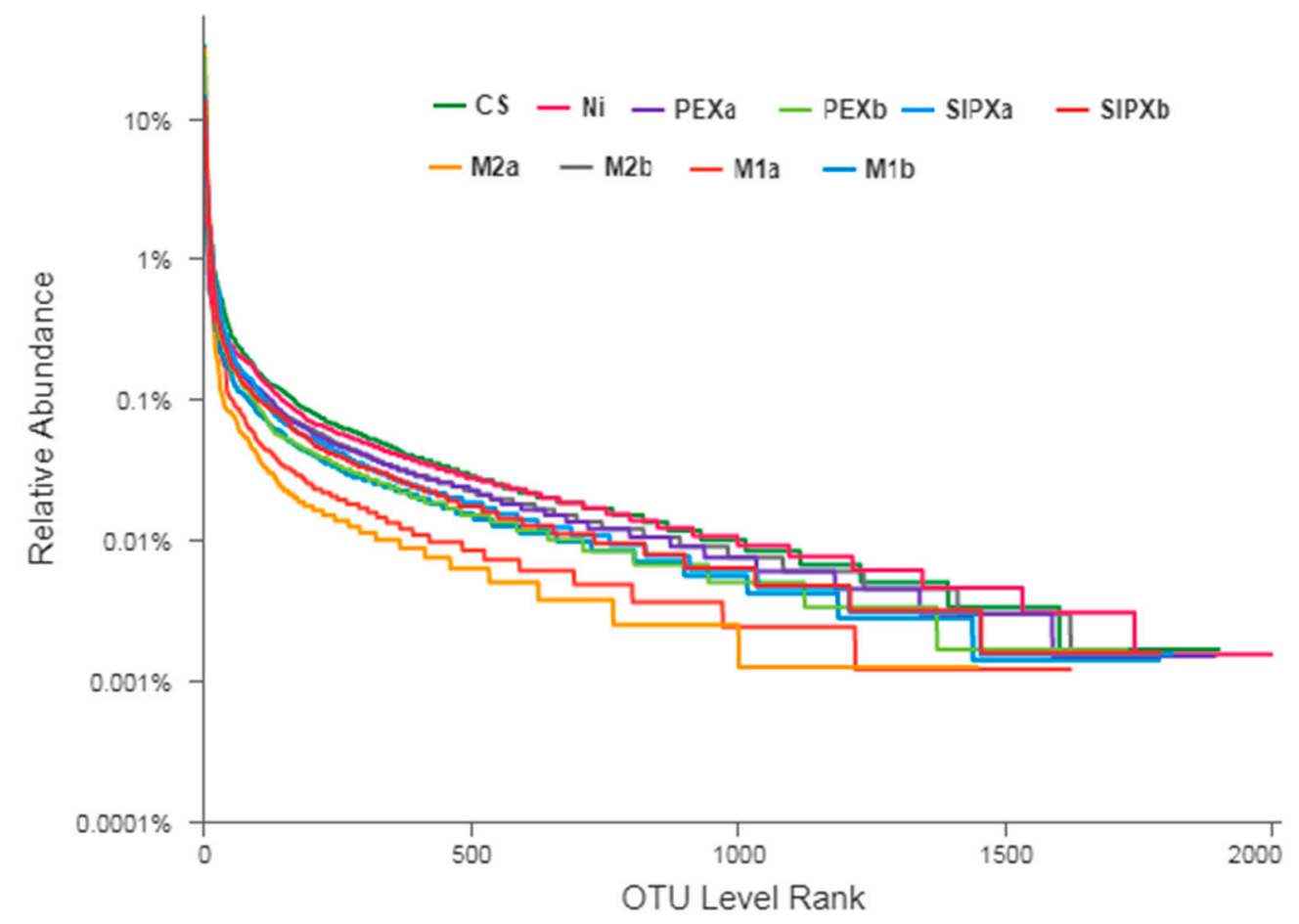

Figure 1. Rank abundance curves of bacterial communities under different soil treatments: Control samples (CS), soil treated with $300 \mu \mathrm{g} \mathrm{Ni} \cdot \mathrm{g}^{-1}$ (Ni), $50 \mu \mathrm{g} \mathrm{PEX} \mathrm{g}{ }^{-1}$ (PEXa), $100 \mu \mathrm{g}$ PEX g ${ }^{-1}(\mathrm{PEXb})$, $50 \mu \mathrm{g}$ SIPX g ${ }^{-1}$ (SIPXa), $100 \mu \mathrm{g}$ SIPX g ${ }^{-1}$ (SIPXb), and soil treated with binary mixtures of $300 \mu \mathrm{g} \mathrm{Ni} \mathrm{g}^{-1}$ and $50 \mu \mathrm{g} \mathrm{PEX} \mathrm{g}^{-1}$ (M1a), $100 \mu \mathrm{g} \mathrm{PEX} \mathrm{g}^{-1}$ (M1b), $50 \mu \mathrm{g}$ SIPX g ${ }^{-1}$ (M2a), and $100 \mu \mathrm{g}$ SIPX g ${ }^{-1}$ (M2b). In the horizontal direction, the abundance of the species is reflected by the width of the curve. The larger the curve is on the horizontal axis, the higher the species abundance. The shape of the curve (smoothness) reflects the uniformity of the species in the sample, the curve. The more gradual, the more uniform the distribution of the species. 
Exposure to a xanthate dose of $100 \mu \mathrm{g} \cdot \mathrm{g}^{-1}$ soil was more harmful than the exposure to $50 \mu \mathrm{g} \cdot \mathrm{g}^{-1}$ soil (e.g., the Shannon diversity index values equal 5.1 and 4.32, respectively for a xanthate dose of 50 and $100 \mu \mathrm{g} \cdot \mathrm{g}^{-1}$ soil, respectively). In contrast, mixtures containing a xanthate dose of $100 \mu \mathrm{g} \cdot \mathrm{g}^{-1}$ soil were the less adverse (e.g., 1621 OTUs and 1787 OTUs in case of $50 \mu \mathrm{g} \cdot \mathrm{g}^{-1}$ and $100 \mu \mathrm{g} \cdot \mathrm{g}^{-1}$ in the mixture, respectively). As it was observed with the microcalorimetric analysis [29], these results may suggest that increasing the concentration of xanthates in the soil can lead to higher toxic effects. This is consistent with the recently observed dose-response relationship with regards to the inhibition of the soil microbial activity by xanthates $[29,36]$. Conversely, the same increase in the xanthates' concentration in the mixture with nickel does not necessarily lead to the magnification of the toxic effect. This may be explained by the affinity and interaction between xanthates and metals that may result in the formation of complex metal/xanthates with different interaction mechanisms from those of the individual mixture components.

\subsection{Similarity and Differences}

From the Venn diagram analysis on the OTU level (Figure 2), samples are more similar (high number of shared bacterial species) than they are unique. Both control samples and Ni-treated samples shared more OTUs with xanthate treatments than with the Ni/xanthate treatments. For example, the control sample shared $61 \%$ and $51.6 \%$ of the total OTUs number with xanthate-treated samples and $\mathrm{Ni} /$ xanthate-treated samples, respectively. Similarly, Ni-treated samples shared $61.9 \%$ and $52.4 \%$ of the total OTUs with the xanthates and mixture treatments. The high number of shared OTUs may indicate the existence of a high number of bacterial species that can adapt to similar conditions [40] of Ni and xanthate pollution.

The variations observed between samples are in line with the principal coordinate analysis (PCoA) plot on the OTUs level (Figure 3A) that explained $68.80 \%$ of the observed variations. Based on the PCoA plot on the OTUs level and the hierarchical clustering tree on the species level (Figure 3B), samples can be grouped into four distinct categories: (1) control sample (C); (2) Ni-treated samples (Ni); (3) xanthate-treated samples (PEXa, PEXb, SIPXa, and SIPXb); and (4) Ni/xanthate-treated samples (M1a, M1b, M2a, and M2b).

\subsection{Taxonomic Composition}

Of the 31 phyla and 66 classes observed from all samples, eight phyla (Figure 4) and 13 classes (Table A1) reached a proportion of $1 \%$ of the total classified sequences in at least one sample. The five most dominant phyla, representing $96.31 \%$ of the whole bacterial community, were Proteobacteria (54.16\%), Firmicutes (17.51\%), Actinobacteria $(15.59 \%)$, Acidobacteria $(4.87 \%)$, and Chloroflexi (4.16\%). The remaining part comprised less abundant phyla, including Bacteroidetes $(0.93 \%)$, Gemmatimonadetes $(0.81 \%)$, Nitrospirae $(0.72 \%)$, Planctomycetes $(0.30 \%)$, Verrucomicrobia $(0.25 \%)$, Tectomicrobia $(0.16)$, and Saccharibacteria (0.109). Proteobacteria comprised four of the 13 most dominant classes, including Gammaproteobacteria (26.5\%), Betaproteobacteria (15.97\%), Alphaproteobacteria $(10.45 \%)$, and Deltaproteobacteria (1.25\%) (Figure 4). From these results, Gammaproteobacteria can be considered as the Proteobacteria class most abundant and adapted to xanthates. This class was more abundant at a xanthate dose of $100 \mu \mathrm{g} \cdot \mathrm{g}^{-1}$ soil than at a xanthate dose of $50 \mu \mathrm{g} \cdot \mathrm{g}^{-1}$ soil. As it is for Betaproteobacteria class, Gammaproteobacteria did not show a significant difference between the xanthates doses and their mixed-chemicals doses. The proportion of Proteobacteria in Ni-treated samples (15\%) was lower than that recently observed in arsenic-contaminated soil where it was the dominant phylum (29-38\% abundant), Alphaproteobacteria and Gammaproteobacteria being the most and least abundant classes [55]. 
(A)
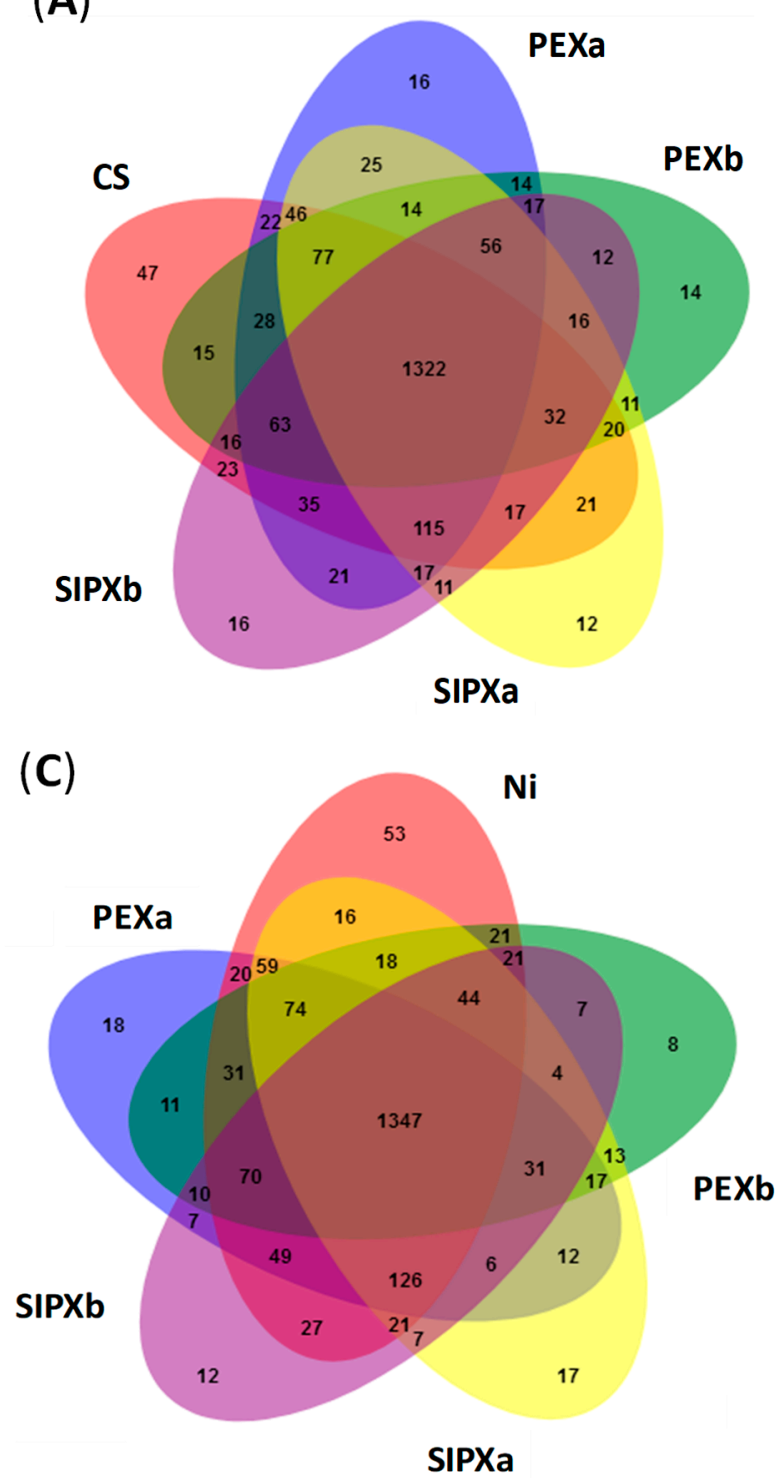

(B)

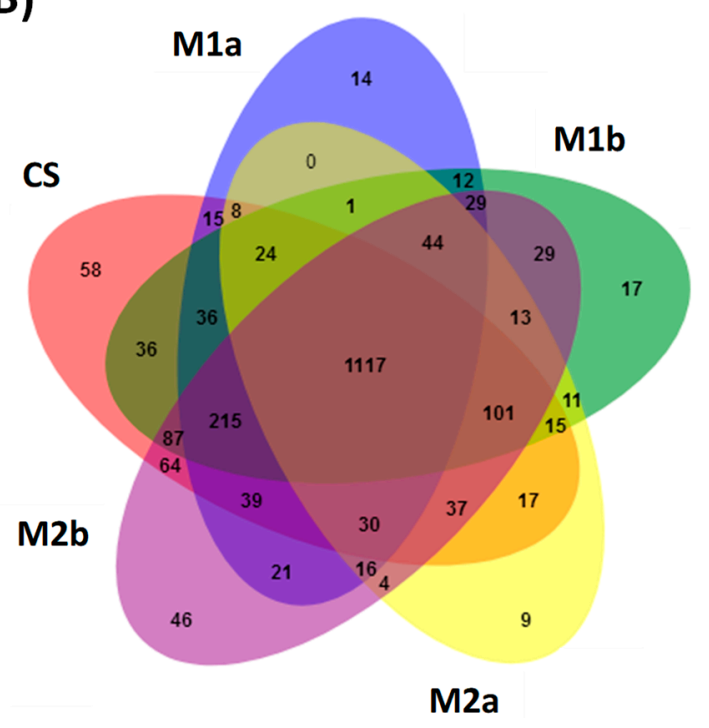

(D)

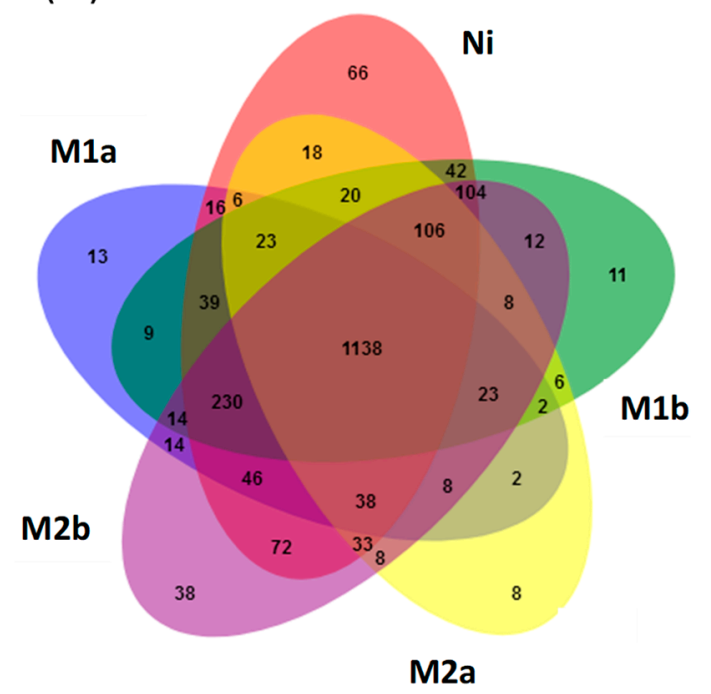

Figure 2. Overlap of the bacterial communities from different samples based on the unique and shared OTUs ( $97 \%$ similar) between different treatments: control samples and single xanthates (A), control sample and Mixed-chemicals (B), single Ni and xanthates (C), and single Ni and mixed-chemicals (D). The control sample and Ni-treated samples shared less OTUs number with the mixture-treated samples than with the single xanthate-treated samples. See Table 1 for sample codes.

The most abundant and proportionally different bacterial classes between the xanthate-treated samples and their corresponding mixtures-treated samples were presented, both in the case of $50 \mu \mathrm{g} \cdot \mathrm{g}^{-1}$ soil (Figure 5A) and in the case of $100 \mu \mathrm{g} \cdot \mathrm{g}^{-1}$ soil (Figure $5 \mathrm{~B}$ ). The number of these classes was higher in the case of a xanthate dose of $50 \mu \mathrm{g} \cdot \mathrm{g}^{-1}$ soil (14 classes) than in the case of a xanthate dose of $100 \mu \mathrm{g} \cdot \mathrm{g}^{-1}$ soil (five classes). Since the Ni amount was the same in both cases, the observed variations can be attributed to the variation in the xanthate dose. 
(A)

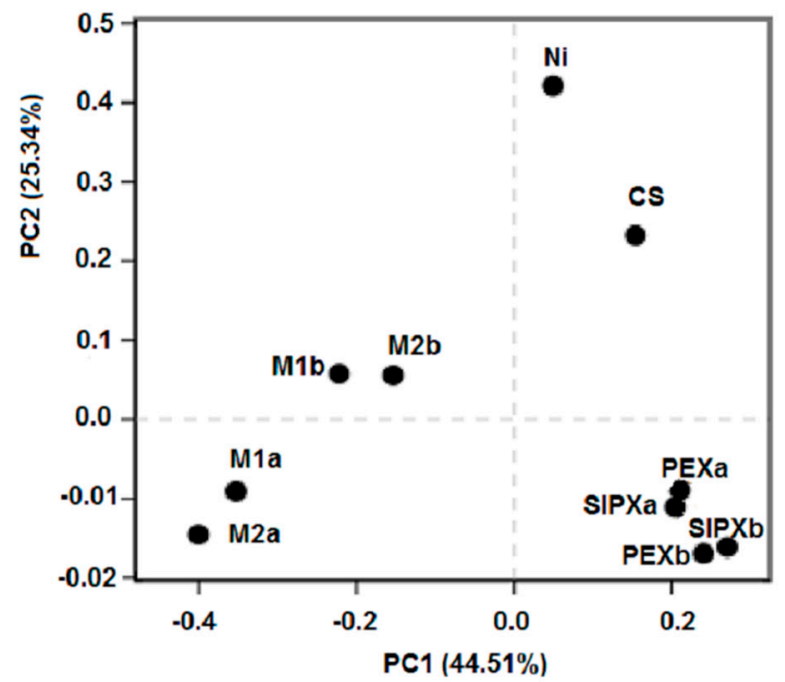

(B)

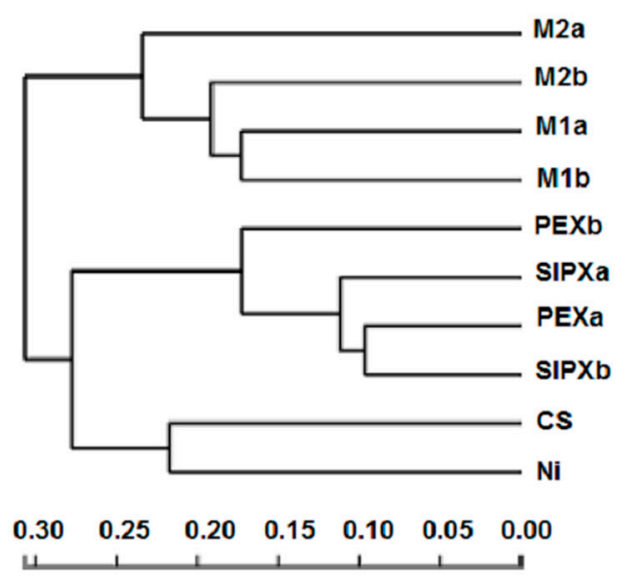

Figure 3. Distance and similarity based on the principal coordination analysis (PCoA) on OTUs analysis level (A) and samples' hierarchical clustering tree on the species analysis level (B). The closer the two samples are on the PCoA plot, the more similar the composition of the two samples' species. The length of the branches in the hierarchical tree represents the distance between samples. See Table 1 for sample codes.

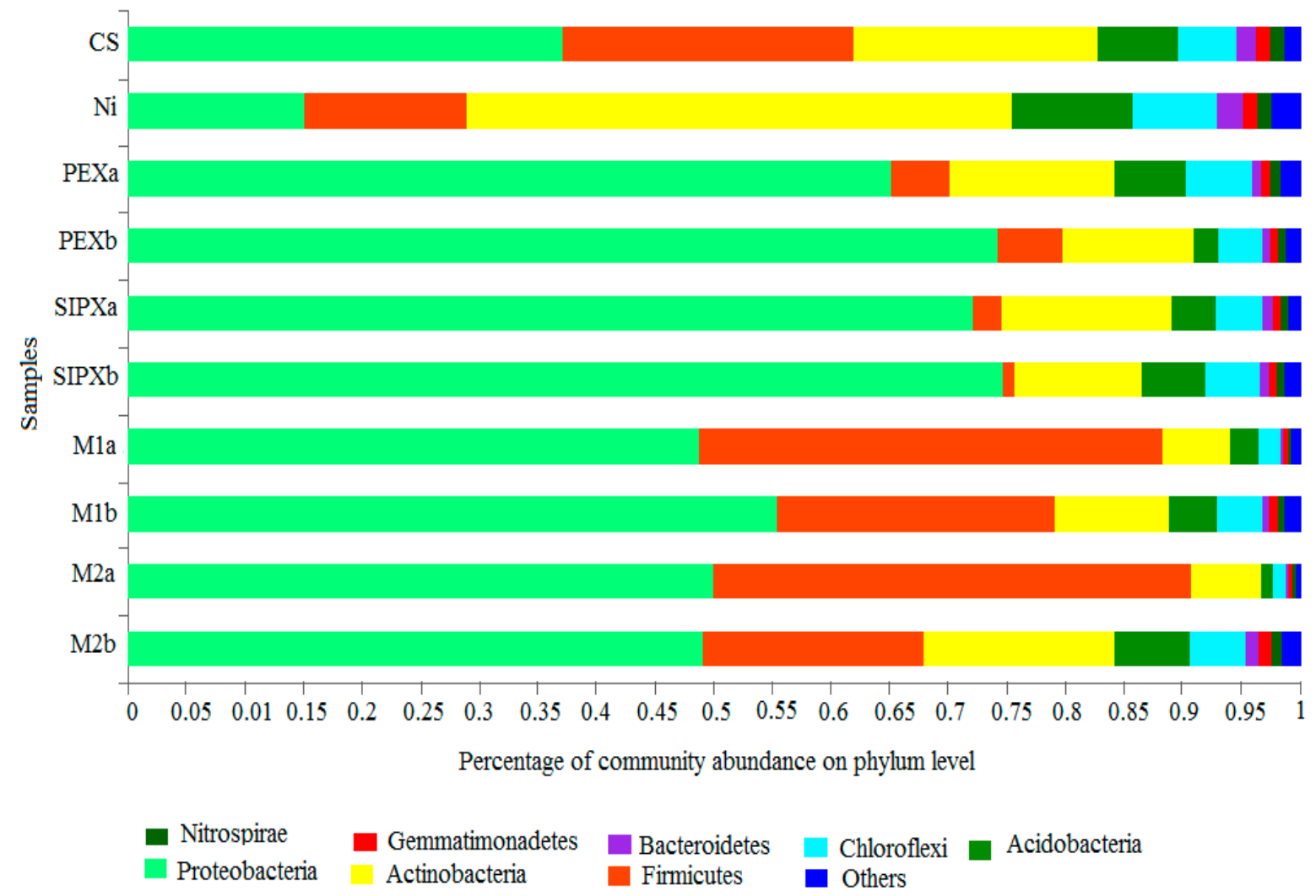

Figure 4. Community bar plots of the relative abundance of the major phyla across all samples. The sequences abundance is above $0.05 \%$ in at least one sample, the rest of the sequences are merged and named as "others". Sequences that could not be classified into any known phylum were labeled "norank" or "unclassified". See Table 1 for sample codes. 


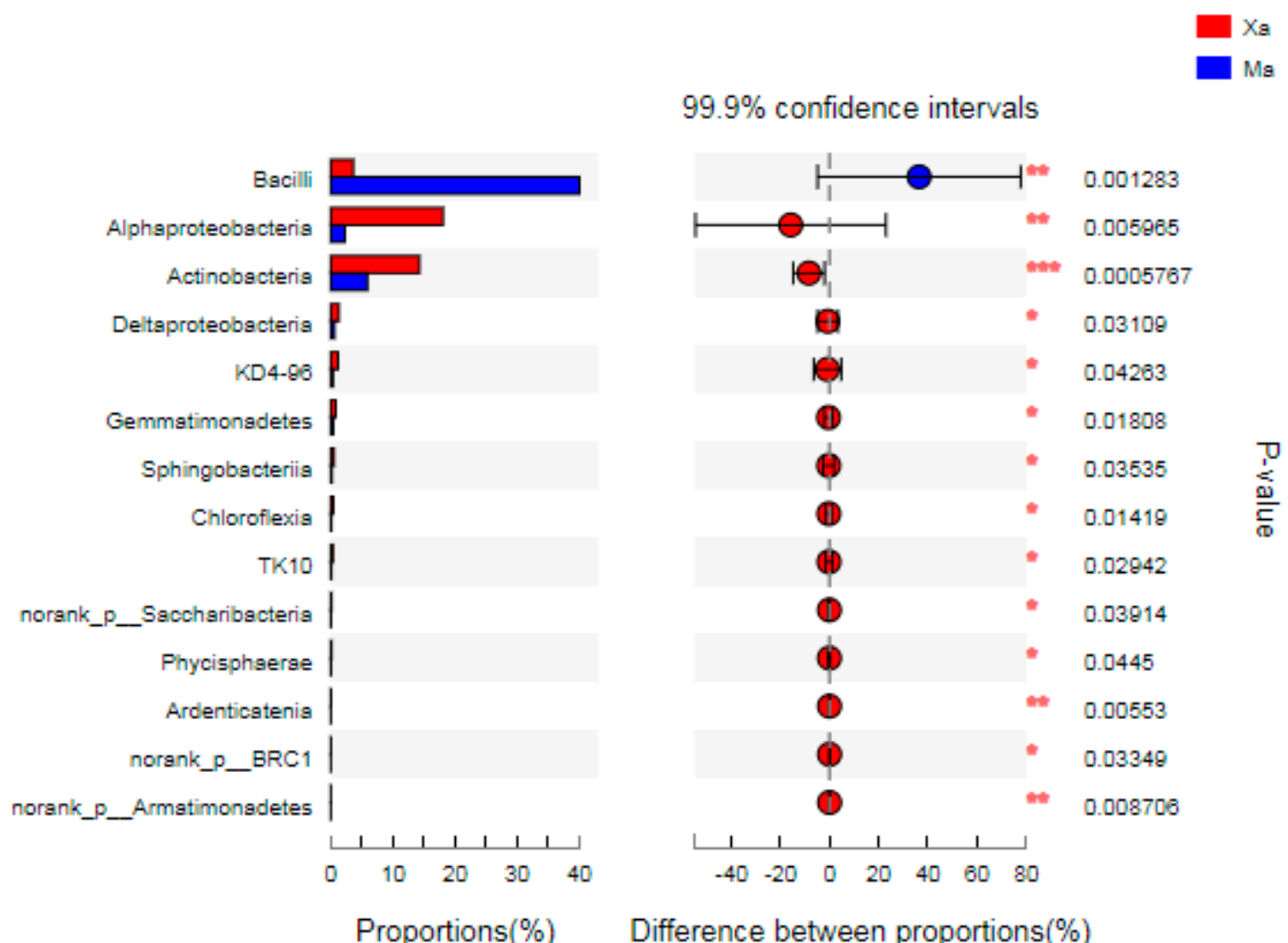

(A)

$99.9 \%$ confidence intervals
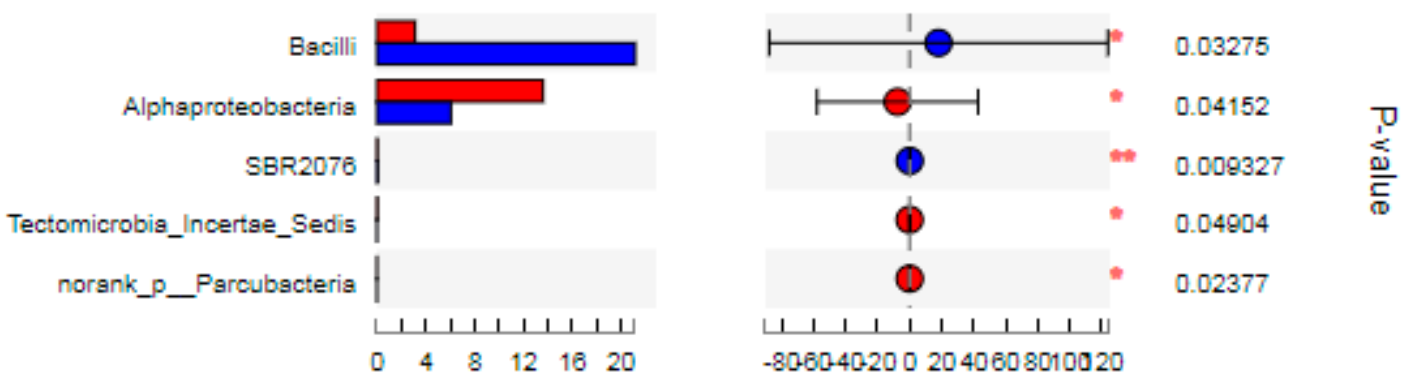

Proportions(\%) Difference between proportions(\%)

(B)

Figure 5. Student's $t$-test bar plot representing the most abundant and significantly different bacterial classes between the xanthate-treated samples and their corresponding mixtures-treated samples. Comparison was made between samples treated with a xanthate dose of $50 \mu \mathrm{g} \cdot \mathrm{g}^{-1}$ (Xa) and the samples treated with the mixtures containing the same xanthate dose, $50 \mu \mathrm{g} \cdot \mathrm{g}^{-1}(\mathrm{Ma})(\mathrm{A})$ and between samples treated with a xanthate dose of $100 \mu \mathrm{g} \cdot \mathrm{g}^{-1}(\mathrm{Xb})$ and the samples treated with the mixtures containing the same xanthate dose, $100 \mu \mathrm{g} \cdot \mathrm{g}^{-1}(\mathrm{Mb})(\mathbf{B})$. Each category comprises four samples.

Most previous studies have reported Proteobacteria as one of the largest phyla within prokaryotes and the leading bacterial community in the soil $[40,44]$ and in the marine ecosystem [56]. It comprises the majority of Gram-negative bacteria, morphologically, physiologically and metabolically largely diversified [57,58], including phototrophs, heterotrophs, and chemolithotrophs, as well as numerous pathogens for humans, animals, and plants [59]. Its dominance was reported in soil contaminated by 
polyaromatic hydrocarbons (PAHs) [60,61] and oil [59]. In this study, its low abundance (15.06\%) was observed in Ni-treated samples. It is well known that organic compounds are subject to various biotic and abiotic decomposition processes, the main one being attributed to the microbial mediation [62-65].

Proteobacteria members have been reported to be among the bacteria which are able to decompose chemical compounds that can serve as a source of energy and metabolites [66]. Such capability may explain the predominance of Proteobacteria in xanthate-treated samples. The families Enterobacteriaceae, Burkholderiaceae, Methylobacteriaceae, Moraxellaceae, and Rhizobiaceaae were found more abundant in xanthate-treated samples than in Ni-treated samples, while the families Pseudomonadaceae and Xanthomonadaceae exhibited higher proportion the Ni/xanthate-treated soil (Figure A1).

With regard to the Firmicutes phylum, it comprised two of the 13 most dominant classes, Bacilli (17.24\%) and Clostridia (0.28\%). Its highest and lowest proportions in the amended samples were observed in $\mathrm{Ni} /$ xanthate-treated samples (18.85-40.72\%) and in xanthate-treated samples $(0.81-5.5 \%)$, respectively. The Firmicutes phylum constitutes a rarely dominant group in the natural environment [67,68], and comprises the majority of gram-positive and endospore-forming bacteria [64]. Some of its members may take advantage of their secondary produced metabolites to cope with stressful conditions, including heavy metal polluted soil [43]. Ecologically, Firmicutes constitute a very important bacterial group, comprising biosurfactant-producing bacteria that are explored for the bioremediation of petroleum hydrocarbon-contaminated soils [69]. They are also involved in various processes, such as cellular metal sequestration [70], iron reduction [71], and fermentation reactions [70,72]. In this study, Bacillaceae family, one of the most involved microbes in those functions, has the highest abundance in the mixture-treated samples (Fig.A1). The second abundant Firmicutes family in the mixture-treated samples was Planococcaceae, accounting for $2.79-14.88 \%$, while it accounted for less than $1 \%$ in the Ni-treated samples. In light of these results, a simultaneous presence of $\mathrm{Ni}$ and xanthates may lead to the reduction of the sensitivity of the Firmicutes species to xanthates.

Regarding the Actinobacteria phylum, it comprised one of the above mentioned 13 most dominant classes, Actinobacteria, and dominated in Ni-treated samples. This phylum comprises gram-positive and spore-forming bacteria that occur in both terrestrial and aquatic ecosystems [73]. They have been previously identified, with relatively low abundance, in samples from various sources, including agricultural soil $[43,74]$ and heavy metals contaminated soil $[68,75]$. Streptomycetaceae which is one of the most ecologically active Actinobacteria families [76,77] exhibited the highest and lowest proportions in Ni-treated samples and xanthate-treated samples, respectively.

Of the 502 genera obtained from all samples, six genera accounted for more than $50 \%$ of the total sequences, including Cupriavidus (13.34\%), Bacillus (13.05\%), Pseudomonas (10.61\%), unclassified_f_Enterobacteriaceae (5.62\%), Lysobacter (4.41\%), and norank_c_Acidobacteria (3.64\%). The most representative genera, with a proportion of more than $1 \%$ of the whole bacterial community in at least one sample, are shown in Table 3.

Among them, a higher number was observed in the control sample. The most significantly different genera between xanthates and their corresponding mixture with nickel are presented (Figures A2 and A3).

As it was observed on the class level, the number of the most abundant and significantly different bacterial genera between the xanthate-treated samples and their corresponding mixture-treated samples was higher (more than 4.5 times) in the case a xanthate dose of $50 \mu \mathrm{g} \cdot \mathrm{g}^{-1}$ soil (Figure A2) than in the case of a xanthate dose of $100 \mu \mathrm{g} \cdot \mathrm{g}^{-1}$ soil (Figure A3). 
Table 3. Relative abundance of the major genera across all the analyzed samples. The sequence's abundance is above $0.1 \%$ in at least one sample, the rest of the sequences are merged and named as "others". Sequences that could not be classified into any known genus were labeled "norank" or "unclassified". See Table 1 for sample codes.

\begin{tabular}{|c|c|c|c|c|c|c|c|c|c|c|}
\hline \multirow{2}{*}{ Bacterial Genus } & \multicolumn{10}{|c|}{ Relative Abundance of Each Bacterial Genus Per Sample } \\
\hline & CS & $\mathrm{Ni}$ & PEXa & PEXb & SIPXa & SIPXb & M1a & M1b & M2a & M2b \\
\hline Cupriavidus & 0.83 & 0.08 & 14.68 & 7.55 & 17.53 & 12.84 & 19.19 & 5.06 & 36.51 & 20.33 \\
\hline Bacillus & 19.10 & 10.54 & 3.31 & 4.74 & 1.79 & 0.41 & 19.93 & 19.40 & 31.90 & 12.81 \\
\hline Pseudomonas & 0.11 & 0.05 & 2.00 & 3.51 & 0.74 & 1.08 & 21.87 & 37.37 & 7.55 & 12.86 \\
\hline unclassified_f__Enterobacteriaceae & 1.76 & 0.00 & 11.06 & 27.23 & 5.82 & 13.28 & 0.50 & 1.17 & 0.07 & 0.06 \\
\hline Lysobacter & 6.37 & 0.70 & 5.84 & 2.95 & 13.82 & 13.81 & 1.00 & 0.70 & 1.12 & 1.35 \\
\hline norank_c_Acidobacteria & 5.03 & 8.01 & 4.82 & 1.50 & 2.82 & 4.17 & 2.01 & 3.34 & 0.70 & 4.95 \\
\hline Microvirga & 5.45 & 0.83 & 6.62 & 3.23 & 8.55 & 5.65 & 0.32 & 1.01 & 0.27 & 0.87 \\
\hline Domibacillus & 0.15 & 0.33 & 0.06 & 0.03 & 0.00 & 0.00 & 13.42 & 2.19 & 5.69 & 0.34 \\
\hline Enterobacter & 0.60 & 0.01 & 5.45 & 7.74 & 4.36 & 6.89 & 1.09 & 0.67 & 0.16 & 0.16 \\
\hline Acinetobacter & 1.30 & 0.00 & 2.70 & 4.59 & 1.67 & 5.14 & 0.20 & 1.11 & 0.36 & 0.03 \\
\hline unclassified_f__Micrococcaceae & 0.36 & 11.78 & 0.29 & 0.12 & 0.35 & 0.24 & 0.18 & 0.27 & 0.09 & 0.54 \\
\hline Sphingomonas & 3.64 & 1.07 & 0.54 & 0.56 & 2.31 & 1.46 & 0.23 & 0.44 & 0.21 & 0.83 \\
\hline Pseudarthrobacter & 0.79 & 4.71 & 0.62 & 0.27 & 0.75 & 0.60 & 0.37 & 0.73 & 0.23 & 1.17 \\
\hline norank_o_JG30-KF-CM45 & 1.14 & 1.68 & 1.48 & 1.12 & 0.85 & 1.10 & 0.39 & 0.91 & 0.29 & 1.13 \\
\hline Isoptericola & 1.29 & 7.15 & 0.24 & 0.21 & 0.66 & 0.17 & 0.17 & 0.06 & 0.10 & 0.14 \\
\hline norank_c_KD4-96 & 1.19 & 1.85 & 1.30 & 0.66 & 1.04 & 1.20 & 0.46 & 0.95 & 0.22 & 1.11 \\
\hline norank_c_Actinobacteria & 0.85 & 1.45 & 1.12 & 0.55 & 1.13 & 1.10 & 0.71 & 0.98 & 0.22 & 1.25 \\
\hline Gaiella & 1.42 & 1.31 & 0.98 & 0.99 & 0.97 & 0.82 & 0.39 & 0.77 & 0.40 & 1.27 \\
\hline Ensifer & 0.55 & 0.19 & 2.81 & 2.12 & 1.60 & 1.72 & 0.07 & 0.26 & 0.05 & 0.17 \\
\hline norank_o_Gaiellales & 1.23 & 1.03 & 0.98 & 0.94 & 0.94 & 0.71 & 0.39 & 0.67 & 0.35 & 1.25 \\
\hline Streptomyces & 0.82 & 2.02 & 1.07 & 0.31 & 1.55 & 0.43 & 0.18 & 0.29 & 0.19 & 0.50 \\
\hline Nitrospira & 1.21 & 1.20 & 0.91 & 0.68 & 0.60 & 0.67 & 0.25 & 0.60 & 0.25 & 0.81 \\
\hline norank_f__Nitrosomonadaceae & 0.87 & 1.11 & 0.73 & 0.67 & 0.70 & 0.48 & 0.34 & 0.67 & 0.25 & 1.03 \\
\hline Paenibacillus & 1.14 & 2.14 & 1.04 & 0.37 & 0.43 & 0.06 & 0.69 & 0.17 & 0.32 & 0.17 \\
\hline Nocardioides & 0.74 & 1.37 & 0.60 & 0.63 & 0.40 & 0.49 & 0.20 & 0.37 & 0.23 & 0.70 \\
\hline Blastococcus & 1.16 & 0.74 & 0.60 & 0.52 & 0.50 & 0.49 & 0.20 & 0.37 & 0.24 & 0.69 \\
\hline Azotobacter & 1.34 & 0.00 & 0.58 & 2.20 & 0.59 & 0.62 & 0.08 & 0.20 & 0.05 & 0.03 \\
\hline Bhargavaea & 0.00 & - & - & - & - & - & 0.24 & 0.38 & 0.15 & 4.34 \\
\hline Microbacterium & 0.31 & 1.81 & 0.19 & 0.10 & 0.10 & 0.15 & 0.20 & 0.04 & 1.58 & 0.17 \\
\hline Agromyces & 1.60 & 1.63 & 0.34 & 0.24 & 0.33 & 0.21 & 0.06 & 0.10 & 0.05 & 0.20 \\
\hline unclassified_f_Rhizobiaceae & 0.28 & 0.03 & 1.33 & 0.97 & 0.90 & 0.90 & 0.00 & 0.10 & 0.00 & 0.01 \\
\hline Pseudoxanthomonas & 0.64 & 0.04 & 0.12 & 0.13 & 1.23 & 0.48 & 0.12 & 0.13 & 0.19 & 0.67 \\
\hline Fictibacillus & 0.24 & 0.03 & 0.12 & 0.02 & 0.05 & 0.00 & 1.71 & 0.03 & 0.22 & 0.23 \\
\hline Achromobacter & 0.07 & 0.03 & 0.50 & 1.08 & 0.10 & 0.14 & 0.09 & 0.12 & 0.04 & 0.12 \\
\hline Others & 6.38 & 35.06 & 24.97 & 21.45 & 24.82 & 22.49 & 12.77 & 18.36 & 9.77 & 27.71 \\
\hline
\end{tabular}

The empty cells (-) indicate that the corresponding bacterial genus is absent or is less than $0.1 \%$ abundant in the corresponding sample.

Based on the proportion of the bacterial species in each sample (Table A2), the most abundant species, with an abundance of more than $5 \%$ of the total classified sequences are unclassified_g_Microvirga and Bacillus selenatarsenatis in the control sample, Bacillus korlensis, unclassified_g_norank_c_Acidobacteria, unclassified_f_Micrococcaceae, and unclassified_g_Isoptericola in the Ni-treated samples, Cupriavidus taiwanensis, unclassified_f_Enterobacteriaceae, unclassified_g_Microvirga, Domibacillus enclensis, and Lysobacter soli, in the xanthate-treated samples, and Cupriavidus taiwanensis, unclassified_g_Pseudomonas, Bacillus korlensis, and Domibacillus enclensis in the $\mathrm{Ni} /$ xanthate-treated samples.

\subsection{Traits of Potential Nickel- and Xanthate-Tolerant Bacteria}

Different bacterial strains have tolerance or resistance to pollutants. Bacteria, such as chemolithoautotrophic Acidithiobacillus ferrooxidans, are metal solubilizers and promote nutrient and metal biogeochemical cycling $[78,79]$. They depend on the oxidation of iron- and sulfur-containing minerals as a source of energy [79]. Such types of organisms are subject to research works to investigate their applicability in the bioaccumulation and removal of soluble and particulate metals [80] and for the degradation of organic pollutants [81] that may constitute promising 
alternative biotechnology to conventional methods for the detoxification of contaminated media. Other organisms are used in biomining for mineral bioleaching and concentration, especially from low-grade ores [82,83]. With respect to Ni-resistant bacteria, studies have reported, among others, bacteria of the genera Bacillus, Streptomyces, Acinetobacter, Burkholderia, Klebsiella, Methylobacerium, Acidithiobacillus, and Leptospirillum [79,80,83-85].

As it was recently reported [86], the mineral bioleaching process can be negatively affected by xanthates that tend to preferably bind to the surface of sulfide minerals, inhibiting the contact and interaction between minerals and the bioleaching microorganisms. The growth, activity, and bioleaching ability of Acidithiobacillus ferrooxidans were depressed by different flotation collectors, ethyl xanthates and isopropyl xanthates, being more adverse than frothers [82]. In contrast, a mixture of three mesophilic bacteria, Acidithiobacillus thiooxidans, Acidithiobacillus ferrooxidans, and Leptospirillum ferrooxidans, exhibited less sensitivity and higher zinc mineral bioleaching than any individual strain [86]. This is consistent with the fact that, to efficiently cope with stressful conditions, as can in the case of exposure to $\mathrm{Ni}$ and xanthates, microbes act synergistically rather than by single strain $[63,83]$.

In this study, considering the bacterial abundance, which is a good indicator of the sensitivity to pollutants, bacteria in the microbial community exposed to $\mathrm{Ni}$ and xanthates fall into four distinct categories. The first category comprised of the most represented bacteria in Ni-treated samples while they are much less abundant in xanthate-treated samples. They include, among others, the genera unclassified_f_Micrococcaceae, Bacillus, norank_c_Acidobacteria, Isoptericola, Pseudarthrobacter, Paenibacillus, Microbacterium, Agromyces, and Nocardioides. Acidobacteria comprises members that are chemoheterotrophs (the most frequent) and photoheterotrophs, and are abundant in various terrestrial and aquatic habitats, including peatlands, acidic soils, and mineral iron-rich habitats [87].

The second category comprises bacteria that were highly abundant in xanthate-treated samples while being much less abundant (less than $0.5 \%$ in general) in Ni-treated samples. The most representative are members of Proteobacteria phylum which demonstrated high abundance in xanthate-treated samples. They include the genera unclassified_f_Enterobacteriaceae, Cupriavidus, Enterobacter, Lysobacter, Microvirga, Acinetobacter, Ensifer, Pseudomonas, unclassified_f_Rhizobiaceae, and Azotobacter. Except for the Cupriavidus genus, this category of bacteria exhibited much lower abundance (less than $1 \%$ in general) in the mixed-chemical treatments. Such a situation may indicate a synergistic toxic effect for $\mathrm{Ni}$ and xanthates. Similar to Bacillus members, bacteria of category 2 are generally multi-resistant to antibiotics [83]. A study of the resistance mechanisms could reveal the existence or non-existence of similar natural response mechanisms to antibiotics and xanthates.

The third group was composed of bacteria which are relatively more abundant in the $\mathrm{Ni} /$ xanthate-treated samples than in the single chemicals-treated samples. In addition to Bacillus and Cupriavidus genera, which are the most representative, other bacteria of this category include genera Bhargavaea, Domibacillus, and Pseudomonas. Pseudomonas was more abundant at a xanthate dose of $100 \mu \mathrm{g} \cdot \mathrm{g}^{-1}$ soil than at a xanthate dose of $50 \mu \mathrm{g} \cdot \mathrm{g}^{-1}$ soil in the mixture. Xanthate-treated samples presented a similar trend. In contrast, Cupriavidus, Bacillus, and Domibacillus exhibited higher abundance in mixtures treatments containing a xanthate dose of $50 \mu \mathrm{g} \cdot \mathrm{g}^{-1}$ soil than in those containing a xanthate dose of $100 \mu \mathrm{g} \cdot \mathrm{g}^{-1}$ soil. Such a situation may explain that increasing the xanthate dose in the mixture with $\mathrm{Ni}$, over a certain limit, can lead to increasing the sensitivity of such bacteria.

The fourth category comprised of bacterial genera that did not show much variation between samples. They include, among others, norank_f_Gemmatimonadaceae, norank_f_Acidimicrobiaceae, norank $f_{-} M S B-1 E 8$, and norank_o_Xanthomonadales. Acidimicrobiaceae bacteria are capable of ammonium $\left(\mathrm{NH}_{4}\right)$ oxidation and play an essential role in denitrification [88]. They are involved in the nitrogen cycle in soil and aqueous environments, similar to Nitrosomonadaceae and Nitrospira members [89]. 


\section{Conclusions}

From the results of this study on the interactive effect of nickel and xanthates, PEX and SIPX, on soil bacterial community diversity and structure, all the applied doses affected, albeit differently, the soil bacterial community, particularly the community structure. Based on the diversity indices' values, xanthates can be considered as more toxic to the soil microbial community than nickel and increasing the xanthate dose in the soil may result in higher toxic effects while the same increase in the xanthate concentration in the mixture with nickel may not necessarily lead to the magnification of the toxicity level. The observed differences in the bacterial abundance in the presence of the same treatment can explain the difference in the bacterial sensitivity to the applied chemicals. Different bacterial strains could be considered as more affected or moderately affected, or less affected by nickel, or xanthates, or their complex mixture. In the real environment, such a situation may be due to differences in the bacterial adaptive mechanisms to these types of exposures, which may predict differences in the bacterial strain survival or adaptation in the presence of these chemicals. Analyzing the functional abundance spectrum will provide important complementary information and extending the analysis to different sites and a wide range of chemicals and doses will allow generating rigorous statistics and general conclusions on the interactive effect of metals and their mineral flotation collectors on the soil microbial community. For the sustainability of mining and ore processing, the observed less affected or potentially resistant bacterial strains could be well explored to determine their resistance capacity level and for their application in biomining and for the prediction and remediation of $\mathrm{Ni}$ and xanthate-polluted soils.

Author Contributions: P.B. designed the study, provided resources, collected data, and wrote the manuscript. Y.Z. was involved in material collection and contributed to the data analysis. H.J. supervised the study and contributed in designing the study and manuscript. All authors read and approved the final manuscript.

Funding: This research was financially supported by the Chinese Government Scholarship via the Chinese Scholarship Council (CSC). The APC was funded by the Burundian Ministry of Higher Education and Scientific Research through the supplementary scholarship to Prudence Bararunyeretse.

Acknowledgments: Authors greatly thank Weizhuo Zhang for his technical assistance.

Conflicts of Interest: The authors declare no conflict of interest. 


\section{Appendix A}

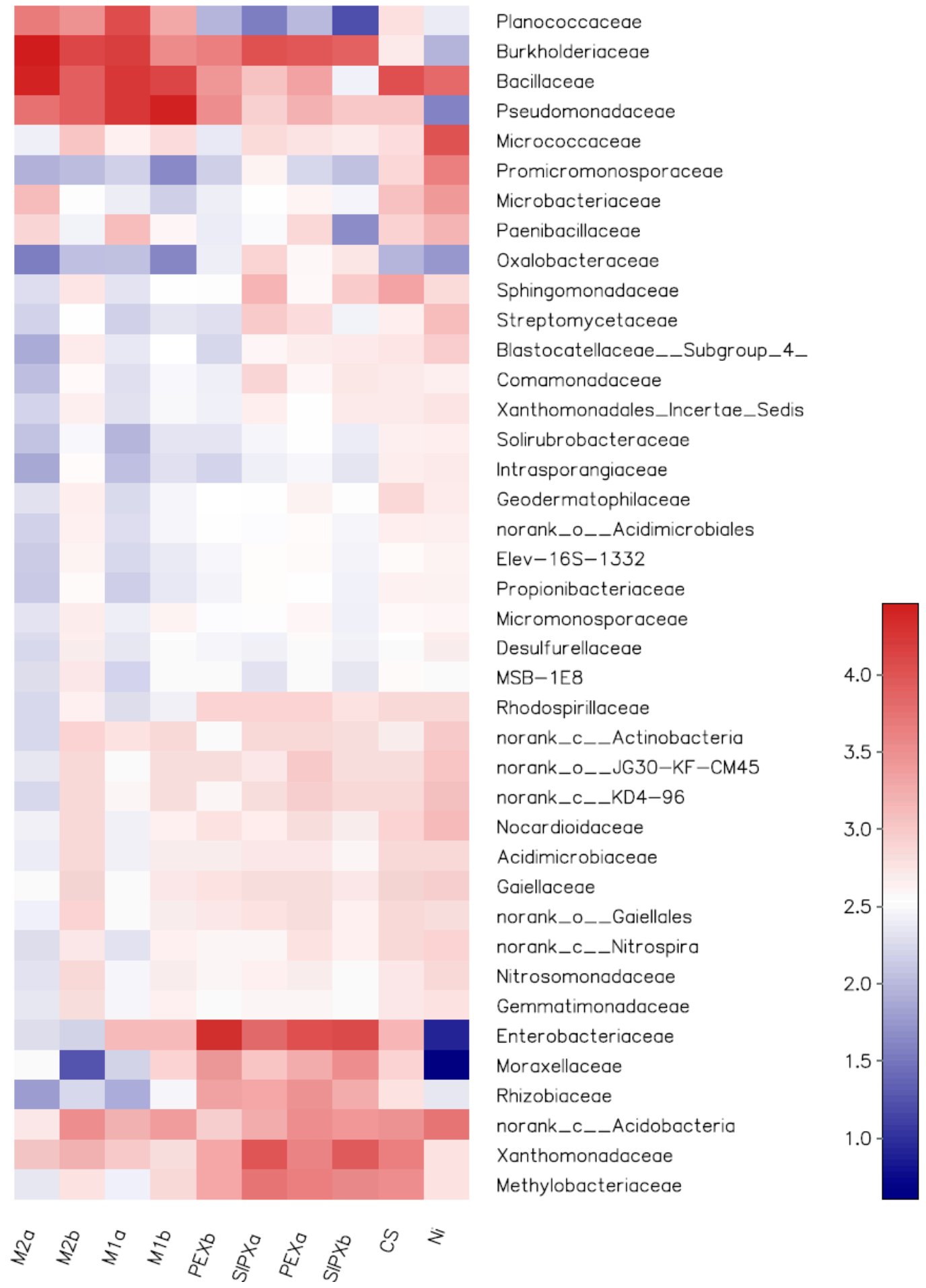

Figure A1. Hierarchically clustered heatmap of distribution for the 40 major bacterial families from different samples: Control sample (C) and samples treated with single nickel (Ni), PEX (PEXa, PEXb), SIPX (SIPXa and SIPXb) and the mixtures of Ni and PEX (M1a and M1b) and PEX (M2a and M2b). Rows and columns stand for each bacterial family and sample, respectively. The relative abundance for each bacterial family was depicted by color intensity as shown at the right of the figure. See Table 1 for sample codes. 


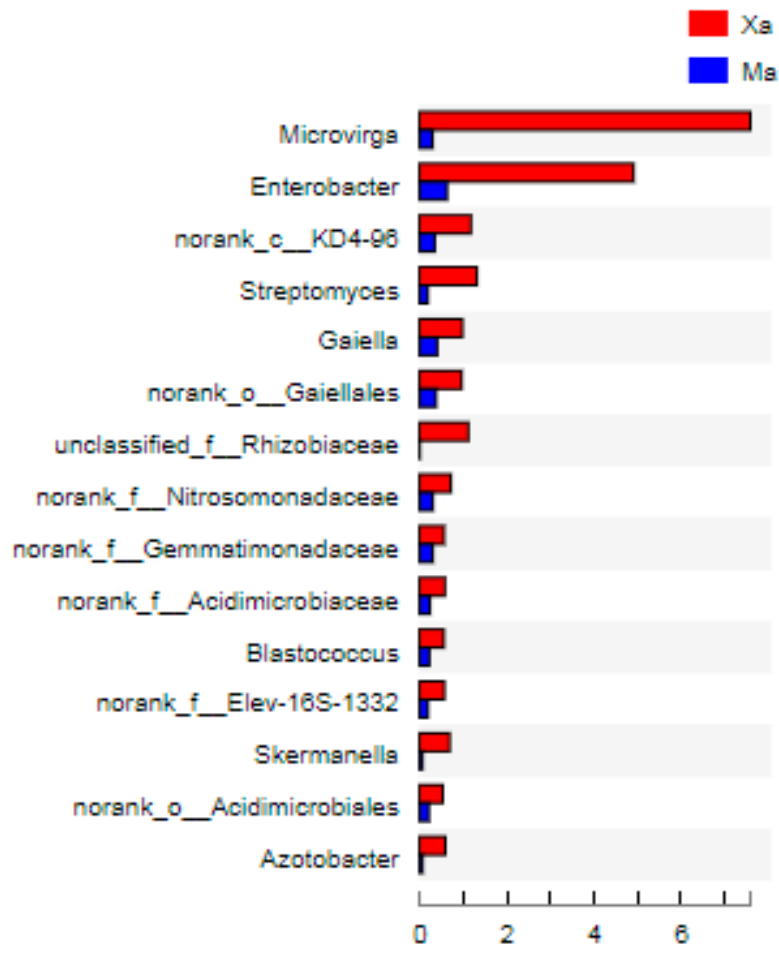

(A)

Proportions(\%)

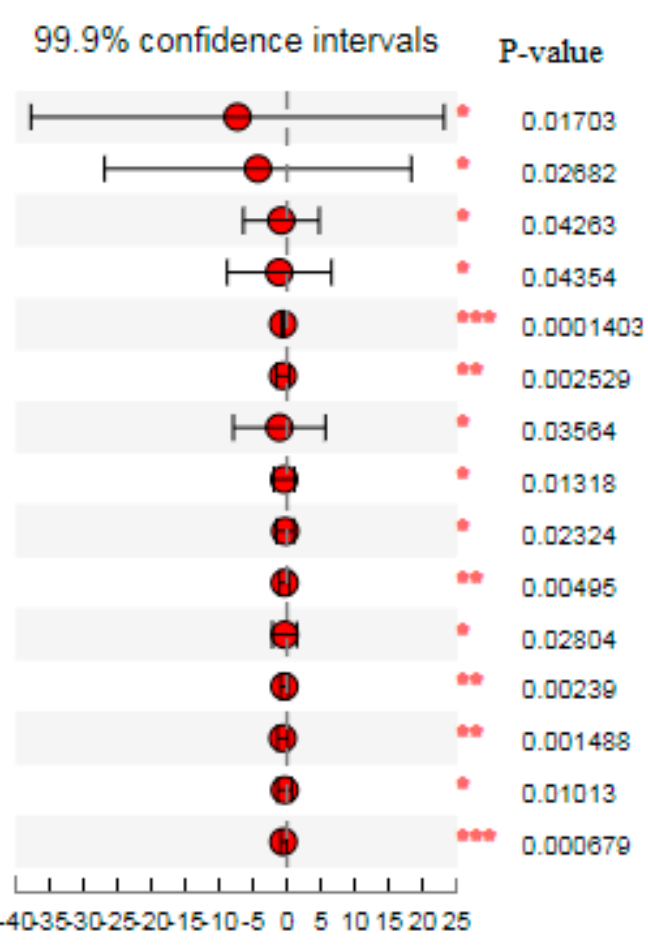

Difference between proportions(\%)

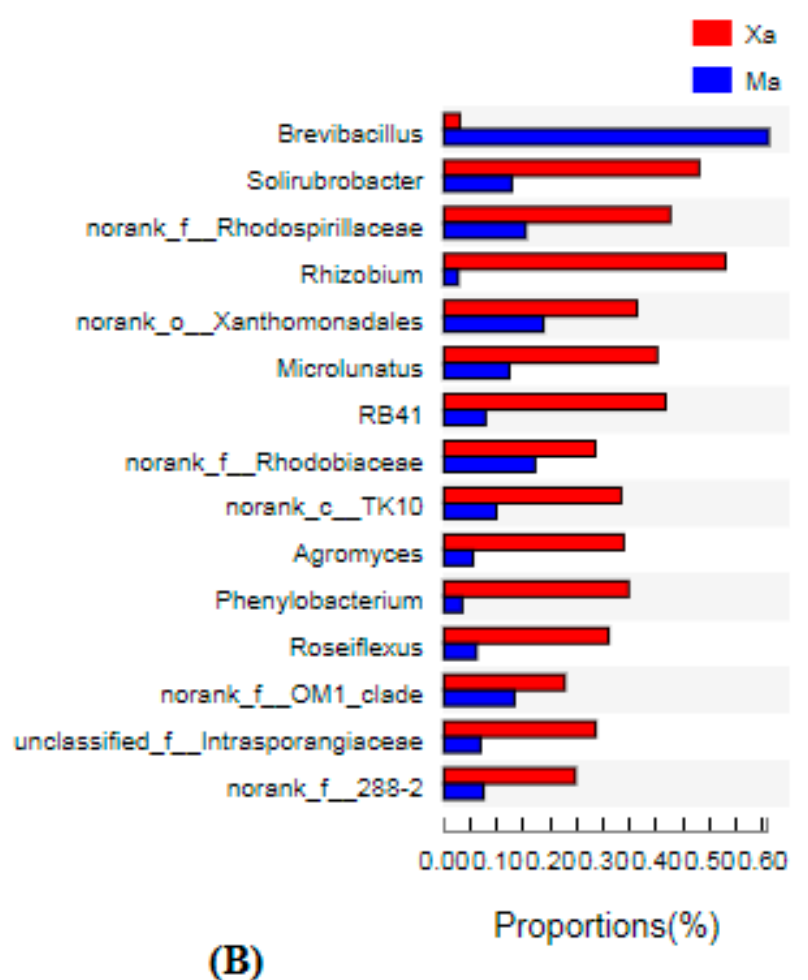

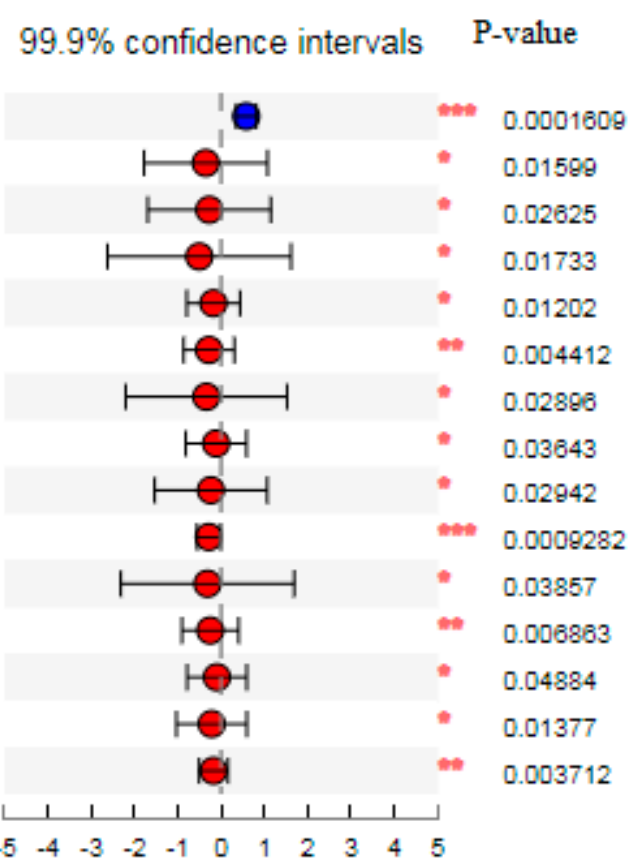

Difference between proportions $(\%)$

Figure A2. Cont. 


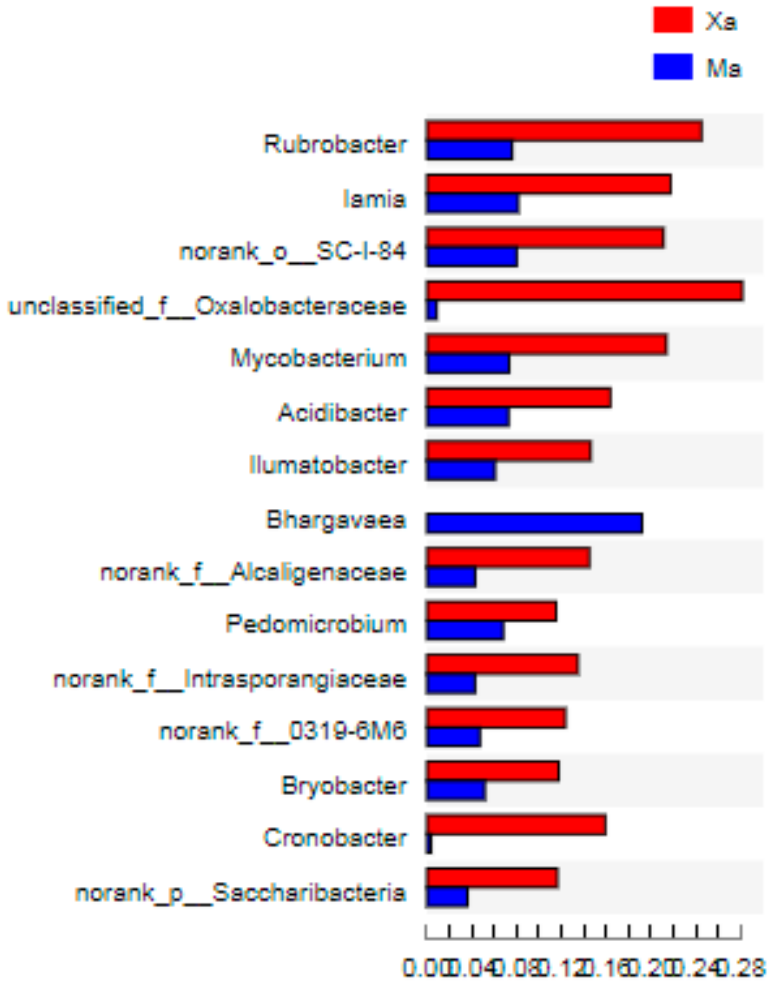

(C)

Proportions(\%)
$99.9 \%$ confidence intervals P-value

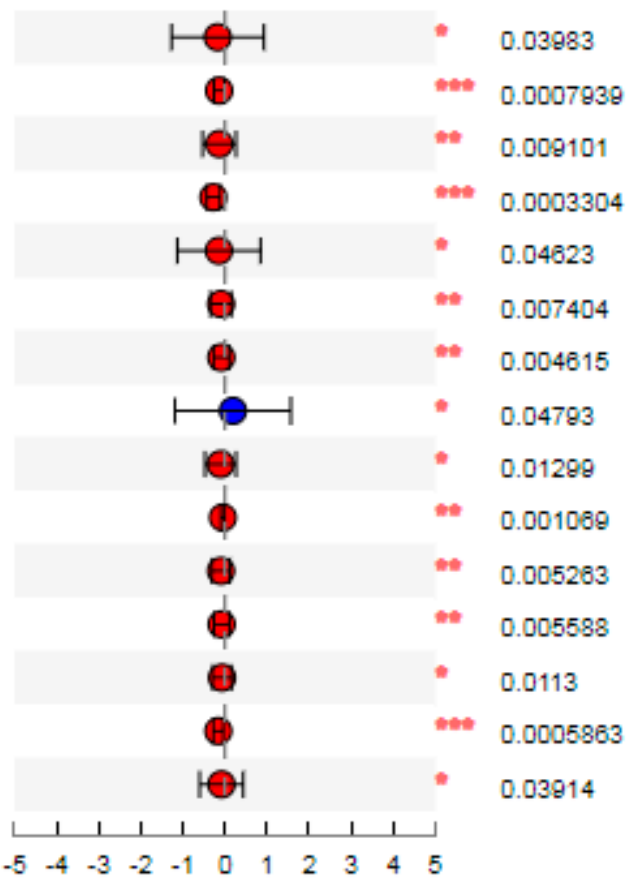

Difference between proportions $(\%)$

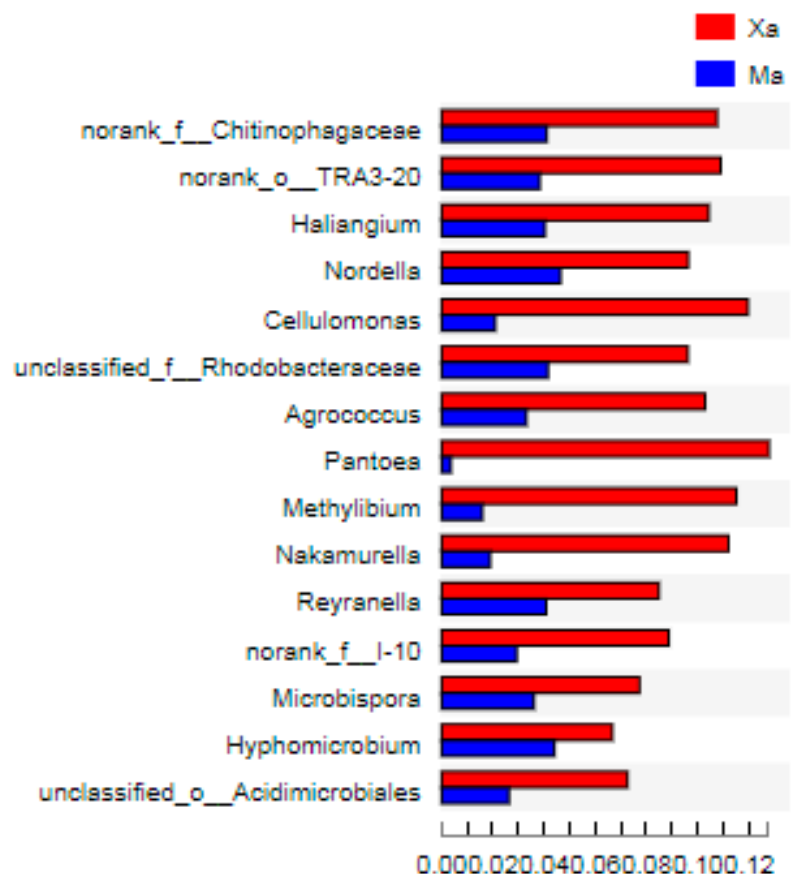

(D)

Proportions(\%)

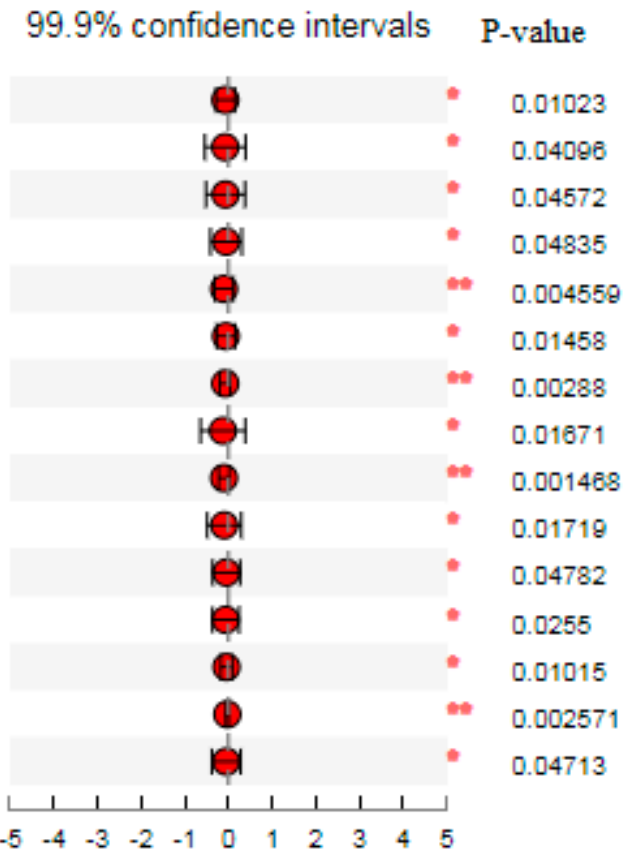

Difference between proportions $(\%)$

Figure A2. Student's t-test bar plot representing the 60 most abundant and significantly different genera between samples treated with xanthate dose of $50 \mu \mathrm{g} \cdot \mathrm{g}^{-1}$ soil (Xa) and their corresponding mixture with $\mathrm{Ni}\left(300 \mu \mathrm{g} \cdot \mathrm{g}^{-1} \mathrm{soil}\right)$ (Ma). Each category is made of four samples). The proportion of the represented genera is $0.58-7.60 \%(\mathbf{A}), 0.23-0.58 \%(\mathbf{B}), 0.12-0.23 \%(\mathbf{C})$, and less than $0.12 \%(\mathbf{D})$. 


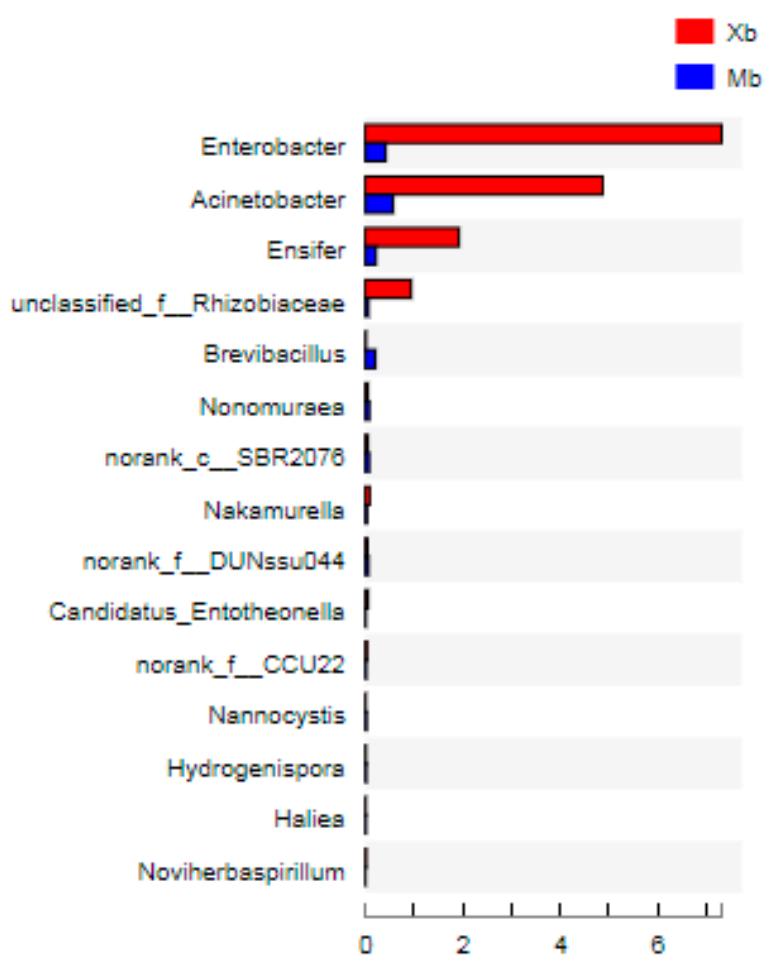

(A)
Proportions(\%)

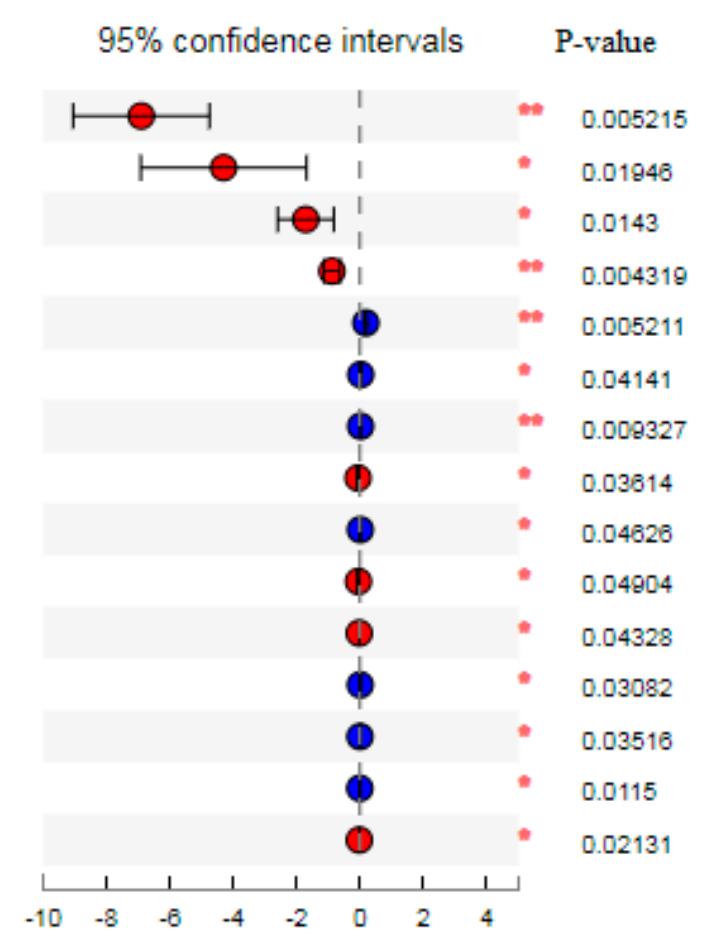

Difference between proportions $(\%)$

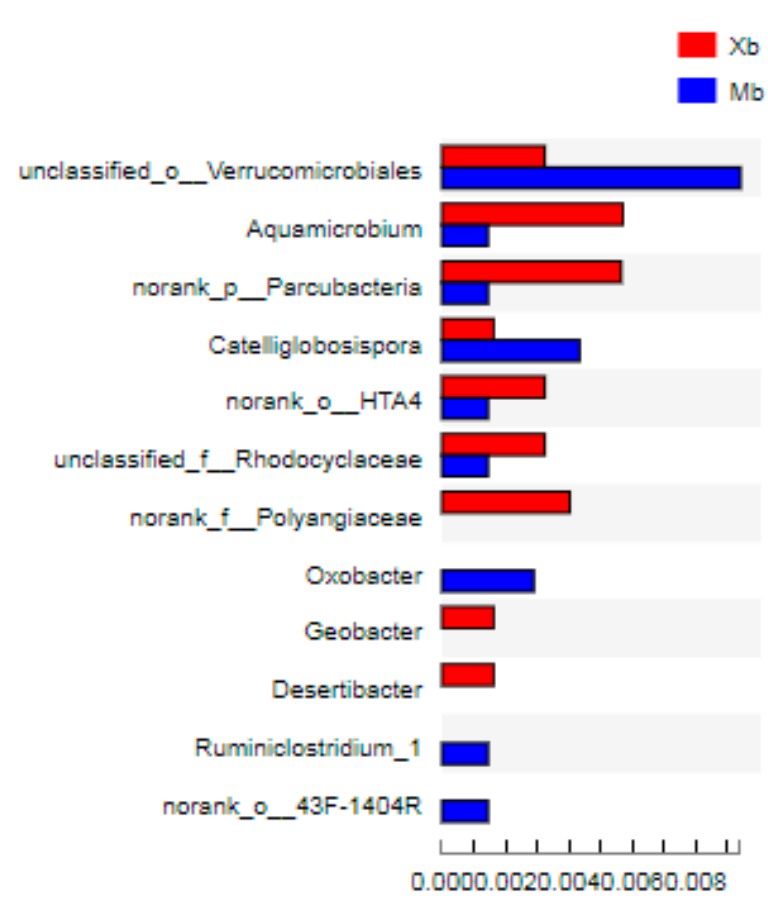

(B)

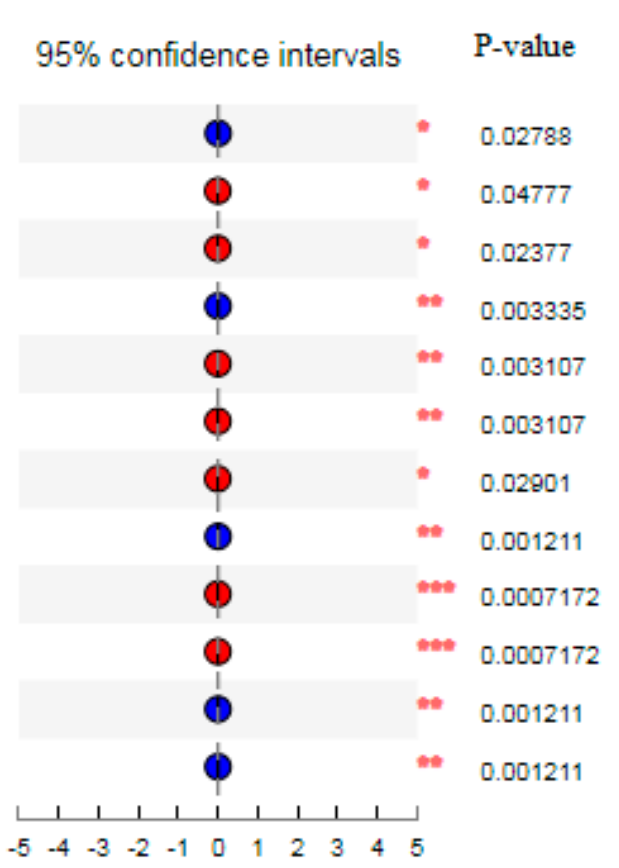

Difference between proportions $(\%)$

Figure A3. Student's t-test bar plot representing the significantly different genera between samples treated with a xanthate dose of $100 \mu \mathrm{g} \cdot \mathrm{g}^{-1}$ soil $(\mathrm{Xb})$ and their corresponding mixtures with $\mathrm{Ni}$ (300 $\mu \mathrm{g} \cdot \mathrm{g}^{-1}$ soil) $(\mathrm{Mb})$. Each category is made of four samples. The proportion of the represented genera is $0.010-7.30 \%(\mathbf{A})$ and less than $0.010(\mathbf{B})$. 


\section{Appendix B}

Table A1. Relative abundance (Percentage of the total classified sequences for each sample) of the major bacterial classes in the absence and presence of single and binary mixture doses of nickel and xanthates (PEX and SIPX). Control samples (CS), samples treated with $300 \mu \mathrm{g} \mathrm{Ni} \mathrm{g}{ }^{-1}$ soil (Ni), $50 \mu \mathrm{g} \mathrm{PEX} \mathrm{g}^{-1}$ soil (PEXa), $100 \mu \mathrm{g}$ PEX·g ${ }^{-1}$ soil (PEXb), $50 \mu \mathrm{g}$ SIPX $\cdot \mathrm{g}^{-1}$ soil (SIPXa), $100 \mu \mathrm{g}$ SIPX g ${ }^{-1}$ soil (SIPXb) and samples treated with binary mixtures of $300 \mu \mathrm{g} \mathrm{Ni} \mathrm{g}^{-1}$ soil and $50 \mu \mathrm{g}$ PEX g ${ }^{-1}$ soil (M1a), $100 \mu \mathrm{g}$ PEX g ${ }^{-1}$ soil (M1b), $50 \mu \mathrm{g} \mathrm{SIPX} \mathrm{g}{ }^{-1}$ soil (M2a), and $100 \mu \mathrm{g} \mathrm{SIPX} \mathrm{g}^{-1}$ soil (M2b).

\begin{tabular}{|c|c|c|c|c|c|c|c|c|c|c|}
\hline \multirow{2}{*}{ Bacterial Class } & \multicolumn{10}{|c|}{ Relative Abundance of Each Bacterial Class Per Sample } \\
\hline & CS & M1a & M1b & M2a & M2b & $\mathbf{N i}$ & PEXa & PEXb & SIPXa & SIPXb \\
\hline Gammaproteobacteria & 14.73 & 25.51 & 42.51 & 10.17 & 17.09 & 2.53 & 29.17 & 50.02 & 30.09 & 43.14 \\
\hline Bacilli & 22.62 & 39.51 & 20.56 & 40.7 & 18.79 & 13.74 & 4.78 & 5.48 & 2.45 & 0.78 \\
\hline Betaproteobacteria & 3.82 & 20.22 & 10.89 & 37.16 & 23.12 & 2.89 & 17.7 & 10.69 & 21.5 & 15.79 \\
\hline Actinobacteria & 20.74 & 5.74 & 8.78 & 6.04 & 16.31 & 46.63 & 14.16 & 11.19 & 14.42 & 10.94 \\
\hline Alphaproteobacteria & 16.79 & 2.4 & 5.01 & 2.14 & 7.11 & 7.64 & 16.86 & 12.42 & 19.3 & 14.81 \\
\hline Acidobacteria & 6.86 & 2.48 & 4.19 & 0.97 & 6.42 & 10.28 & 6.1 & 2.16 & 3.87 & 5.43 \\
\hline Deltaproteobacteria & 1.76 & 0.62 & 1.06 & 0.54 & 1.13 & 2 & 1.43 & 1.11 & 1.18 & 1.01 \\
\hline Thermomicrobia & 1.36 & 0.44 & 1.02 & 0.33 & 1.24 & 1.9 & 1.65 & 1.27 & 0.95 & 1.21 \\
\hline KD4-96 & 1.19 & 0.46 & 0.95 & 0.22 & 1.11 & 1.85 & 1.3 & 0.66 & 1.04 & 1.2 \\
\hline Gemmatimonadetes & 1.22 & 0.44 & 0.76 & 0.33 & 1.19 & 1.21 & 0.8 & 0.67 & 0.78 & 0.7 \\
\hline Nitrospira & 1.21 & 0.25 & 0.6 & 0.25 & 0.81 & 1.2 & 0.91 & 0.68 & 0.6 & 0.67 \\
\hline Sphingobacteriia & 1.2 & 0.15 & 0.29 & 0.17 & 0.56 & 1.36 & 0.45 & 0.38 & 0.58 & 0.45 \\
\hline Anaerolineae & 0.36 & 0.16 & 0.39 & 0.09 & 0.43 & 0.84 & 0.54 & 0.23 & 0.36 & 0.43 \\
\hline Cytophagia & 0.5 & 0.1 & 0.26 & 0.13 & 0.46 & 0.73 & 0.33 & 0.34 & 0.18 & 0.24 \\
\hline Chloroflexia & 0.51 & 0.11 & 0.22 & 0.09 & 0.33 & 0.53 & 0.44 & 0.33 & 0.37 & 0.36 \\
\hline TK10 & 0.39 & 0.11 & 0.27 & 0.09 & 0.34 & 0.51 & 0.37 & 0.25 & 0.29 & 0.29 \\
\hline Gitt-GS-136 & 0.23 & 0.15 & 0.28 & 0.06 & 0.31 & 0.5 & 0.4 & 0.18 & 0.27 & 0.39 \\
\hline Clostridia & 2.23 & 0.04 & 0.06 & 0.02 & 0.06 & 0.06 & 0.12 & 0.07 & 0.06 & 0.04 \\
\hline S085 & 0.24 & 0.14 & 0.19 & 0.07 & 0.34 & 0.3 & 0.24 & 0.22 & 0.19 & 0.24 \\
\hline Spartobacteria & 0.13 & 0.14 & 0.27 & 0.03 & 0.29 & 0.39 & 0.18 & 0.05 & 0.07 & 0.2 \\
\hline Caldilineae: & 0.28 & 0.07 & 0.17 & 0.04 & 0.2 & 0.25 & 0.23 & 0.17 & 0.16 & 0.2 \\
\hline JG30-KF-CM66 & 0.22 & 0.09 & 0.13 & 0.04 & 0.25 & 0.24 & 0.22 & 0.16 & 0.16 & 0.17 \\
\hline Planctomycetacia & 0.14 & 0.09 & 0.13 & 0.03 & 0.21 & 0.33 & 0.18 & 0.07 & 0.1 & 0.12 \\
\hline unclassified_k_norank & 0.12 & 0.07 & 0.14 & 0.03 & 0.16 & 0.21 & 0.14 & 0.1 & 0.12 & 0.13 \\
\hline norank_p__Tectomicrobia & 0.19 & 0.04 & 0.06 & 0.04 & 0.11 & 0.21 & 0.2 & 0.1 & 0.1 & 0.12 \\
\hline norank_p__Saccharibacteria & 0.18 & 0.04 & 0.09 & 0.03 & 0.1 & 0.21 & 0.13 & 0.1 & 0.1 & 0.11 \\
\hline norank_p_LLatescibacteria & 0.08 & 0.05 & 0.1 & 0.02 & 0.14 & 0.21 & 0.14 & 0.05 & 0.07 & 0.11 \\
\hline Phycisphaerae & 0.09 & 0.04 & 0.09 & 0.03 & 0.11 & 0.15 & 0.13 & 0.08 & 0.09 & 0.1 \\
\hline OM190 & 0.05 & 0.04 & 0.05 & 0.01 & 0.08 & 0.12 & 0.08 & 0.04 & 0.06 & 0.07 \\
\hline Ardenticatenia & 0.08 & 0.01 & 0.01 & 0.01 & 0.03 & 0.14 & 0.06 & 0.05 & 0.05 & 0.07 \\
\hline Tectomicrobia_Incertae_Sedis: & 0.07 & & 0.01 & 0.01 & 0.01 & 0.12 & 0.08 & 0.06 & 0.05 & 0.04 \\
\hline Flavobacteriia & 0.03 & 0.02 & 0.03 & 0.01 & 0.03 & 0.04 & 0.03 & 0.03 & 0.12 & 0.05 \\
\hline Chlamydiae & 0.01 & 0.02 & 0.01 & 0 & 0.02 & 0.01 & 0.01 & 0.27 & 0.01 & 0.01 \\
\hline others & 0.39 & 0.22 & 0.44 & 0.09 & 0.62 & 0.84 & 0.47 & 0.28 & 0.25 & 0.39 \\
\hline
\end{tabular}


Table A2. Relative abundance (percentage of the total classified sequences for each sample) of the most representative bacterial species per sample: Control sample (C), and samples treated with single nickel (Ni), PEX (PEXa and PEXa), SIPX (SIPXa and SIPXb), and the mixtures of nickel and PEX (M1a and M1b) and SIPX (M2a and M2b). See Table 1 for sample codes.

\begin{tabular}{|c|c|c|c|c|c|c|c|c|c|c|}
\hline \multirow[t]{2}{*}{ Bacterial Species Name } & \multicolumn{9}{|c|}{ Bacterial Species Abundance (\%) Per Sample } & \multirow[b]{2}{*}{ M2b } \\
\hline & CS & $\mathrm{Ni}$ & PEXa & PEXb & SIPXa & SIPXb & M1a & M1b & M2a & \\
\hline Cupriavidus_taiwanensis & 0.53 & 0.03 & 9.47 & 5.81 & 14.2 & 8.06 & 13.3 & 3.41 & 0.95 & 14.85 \\
\hline unclassified_g_Pseudomonas & 0.11 & 0.05 & 1.98 & 3.46 & 0.74 & 1.08 & 1.9 & 37.37 & 7.55 & 12.86 \\
\hline Bacillus_korlensis & 2.88 & 6.36 & 0.60 & 0.67 & 0.74 & 0.13 & 8.70 & 13.24 & 24.42 & 11.36 \\
\hline unclassified_f_E_Enterobacteriaceae & 1.76 & 0.00 & 11.1 & 27.23 & 5.82 & 13.28 & 0.50 & 1.17 & 0.07 & 0.06 \\
\hline unclassified_g_Microvirga & 5.17 & 0.62 & 6.30 & 3.03 & 8.28 & 5.44 & 0.24 & 0.85 & 0.20 & 0.64 \\
\hline Lysobacter_soli & 2.15 & 0.16 & 5.34 & 2.67 & 7.83 & 8.25 & 0.85 & 0.50 & 0.95 & 1.00 \\
\hline Domibacillus_enclensis & 0.15 & 0.33 & 0.06 & 0.03 & 0.00 & 0.00 & 13.4 & 2.19 & 5.69 & 0.34 \\
\hline unclassified_g_Enterobacter & 0.60 & 0.01 & 5.45 & 7.74 & 4.36 & 6.89 & 1.09 & 0.67 & 0.16 & 0.16 \\
\hline unclassified_g_norank_c__Acidobacteria & 3.27 & 0.43 & 3.14 & 0.96 & 1.87 & 2.77 & 1.32 & 2.19 & 0.45 & 3.25 \\
\hline Ralstonia_pickettii_DTP0602 & 0.11 & 0.05 & 3.95 & 1.20 & 2.16 & 3.49 & 3.95 & 0.89 & 3.20 & 4.03 \\
\hline Bacillus_selenatarsenatis & 8.12 & 1.72 & 0.68 & 2.92 & 0.17 & 0.05 & 2.21 & 3.00 & 0.58 & 0.08 \\
\hline Acinetobacter_nosocomialis & 1.30 & 0.00 & 2.70 & 4.59 & 1.67 & 5.06 & 0.19 & 1.09 & 0.09 & 0.03 \\
\hline unclassified_g_Bacillus & 2.46 & 0.49 & 1.08 & 0.75 & 0.22 & 0.06 & 3.70 & 1.40 & 3.27 & 0.45 \\
\hline unclassified_f_Micrococcaceae & 0.36 & 11.8 & 0.29 & 0.12 & 0.35 & 0.24 & 0.18 & 0.27 & 0.09 & 0.54 \\
\hline unclassified_-g_Cupriavidus & 0.19 & 0.01 & 1.26 & 0.53 & 1.21 & 1.29 & 1.94 & 0.77 & 2.37 & 1.45 \\
\hline Bacillus_idriensis & 2.80 & 0.61 & 0.56 & 0.24 & 0.23 & 0.09 & 2.16 & 1.05 & 1.46 & 0.66 \\
\hline Lysobacter_dokdonensis_DS-58 & 1.68 & 0.33 & 0.22 & 0.16 & 3.89 & 4.03 & 0.06 & 0.11 & 0.03 & 0.15 \\
\hline unclassified_g_Pseudarthrobacter & 0.79 & 4.71 & 0.62 & 0.27 & 0.75 & 0.60 & 0.37 & 0.73 & 0.23 & 1.17 \\
\hline unclassified_g_Isoptericola & 1.29 & 7.15 & 0.24 & 0.21 & 0.66 & 0.17 & 0.17 & 0.06 & 0.10 & 0.14 \\
\hline unclassified_g_Sphingomonas & 3.27 & 0.92 & 0.45 & 0.45 & 1.99 & 1.17 & 0.19 & 0.38 & 0.18 & 0.71 \\
\hline unclassified_g__Streptomyces & 0.81 & 2.02 & 1.07 & 0.31 & 1.55 & 0.43 & 0.18 & 0.29 & 0.19 & 0.50 \\
\hline uncultured_bacterium_g_norank_c_KD4-96 & 0.90 & 1.36 & 0.94 & 0.47 & 0.77 & 0.90 & 0.35 & 0.67 & 0.14 & 0.80 \\
\hline unclassified_g_Bhargavaea & 0.00 & - & - & - & - & - & 0.24 & 0.38 & 0.15 & 4.34 \\
\hline unclassified_g_norank_c_Actinobacteria & 0.44 & 0.76 & 0.58 & 0.28 & 0.57 & 0.57 & 0.31 & 0.52 & 0.12 & 0.64 \\
\hline Ensifer_adhaerens_g_Ensifer & 0.38 & 0.17 & 1.49 & 1.23 & 0.59 & 0.68 & 0.05 & 0.14 & 0.04 & 0.15 \\
\hline unclassified_g__Microbacterium & 0.28 & 0.75 & 0.15 & 0.07 & 0.08 & 0.13 & 0.19 & 0.03 & 1.57 & 0.13 \\
\hline unclassified_g_Ensifer & 0.18 & 0.02 & 1.31 & 0.88 & 1.01 & 1.04 & 0.02 & 0.12 & 0.01 & 0.02 \\
\hline uncultured_bacterium_g_norank_f__Acidimicrobiaceae & 0.74 & 0.60 & 0.46 & 0.48 & 0.45 & 0.36 & 0.19 & 0.36 & 0.18 & 0.59 \\
\hline unclassified_f__Rhizobiaceae & 0.28 & 0.03 & 1.33 & 0.97 & 0.90 & 0.90 & 0.00 & 0.10 & 0.00 & 0.01 \\
\hline unclassified_g_norank_o_JG30-KF-CM45 & 0.50 & 0.72 & 0.67 & 0.47 & 0.33 & 0.48 & 0.17 & 0.42 & 0.12 & 0.51 \\
\hline
\end{tabular}


Table A2. Cont.

\begin{tabular}{|c|c|c|c|c|c|c|c|c|c|c|}
\hline \multirow[t]{2}{*}{ Bacterial Species Name } & \multicolumn{9}{|c|}{ Bacterial Species Abundance (\%) Per Sample } & \multirow[b]{2}{*}{ M2b } \\
\hline & CS & $\mathrm{Ni}$ & PEXa & PEXb & SIPXa & SIPXb & M1a & M1b & M2a & \\
\hline uncultured_Blastococcus_sp_g__Blastococcus & 0.88 & 0.59 & 0.49 & 0.41 & 0.39 & 0.37 & 0.16 & 0.30 & 0.19 & 0.59 \\
\hline uncultured_bacterium_g_norank_f__MSB-1E8 & 0.54 & 0.52 & 0.50 & 0.50 & 0.31 & 0.33 & 0.19 & 0.42 & 0.21 & 0.76 \\
\hline unclassified_g_Nitrospira & 0.71 & 0.70 & 0.58 & 0.41 & 0.36 & 0.38 & 0.15 & 0.33 & 0.13 & 0.46 \\
\hline unclassified_g_norank_o__Gaiellales & 0.58 & 0.45 & 0.46 & 0.45 & 0.44 & 0.35 & 0.20 & 0.31 & 0.15 & 0.54 \\
\hline unclassified_g_Paenibacillus & 0.50 & 1.98 & 0.38 & 0.05 & 0.07 & 0.00 & 0.53 & 0.06 & 0.13 & 0.05 \\
\hline unclassified_g_norank_f__Rhodospirillaceae & 0.57 & 0.50 & 0.38 & 0.40 & 0.47 & 0.34 & 0.16 & 0.31 & 0.15 & 0.51 \\
\hline uncultured_bacterium_g__Skermanella & 0.55 & 0.48 & 0.65 & 0.83 & 0.60 & 0.50 & 0.05 & 0.05 & 0.06 & 0.09 \\
\hline uncultured_bacterium_g_Azotobacter & 1.30 & - & 0.26 & 1.96 & 0.19 & 0.15 & 0.02 & 0.08 & 0.03 & 0.02 \\
\hline uncultured_bacterium_g_Solirubrobacter & 0.62 & 0.62 & 0.43 & 0.27 & 0.36 & 0.29 & 0.09 & 0.24 & 0.13 & 0.41 \\
\hline unclassified_g_Lysobacter & 0.81 & 0.09 & 0.15 & 0.05 & 1.11 & 1.00 & 0.04 & 0.05 & 0.07 & 0.11 \\
\hline Bacillus_marisflavi_g_Bacillus & 0.13 & 0.02 & 0.05 & 0.03 & 0.16 & 0.01 & 1.68 & 0.52 & 0.19 & 0.04 \\
\hline unclassified_g_Pseudoxanthomonas & 0.60 & 0.03 & 0.09 & 0.13 & 1.17 & 0.42 & 0.11 & 0.12 & 0.17 & 0.49 \\
\hline unclassified_g_norank_f_Nitrosomonadaceae & 0.40 & .54 & 0.38 & 0.34 & 0.27 & 0.22 & 0.17 & 0.29 & 0.12 & 0.48 \\
\hline uncultured_actinobacterium_g_Gaiella & 0.51 & 0.45 & 0.36 & 0.34 & 0.31 & 0.26 & 0.12 & 0.28 & 0.14 & 0.44 \\
\hline Fictibacillus_arsenicus & 0.24 & 0.03 & 0.12 & 0.02 & 0.05 & 0.00 & 1.71 & 0.03 & 0.22 & 0.23 \\
\hline uncultured_bacterium_g_Gaiella & 0.37 & 0.42 & 0.32 & 0.35 & 0.34 & 0.28 & 0.14 & 0.26 & 0.14 & 0.43 \\
\hline unculturedAcidobacteriales_bacterium_g_norank_c_Acidobacteria & 0.45 & 0.63 & 0.35 & 0.10 & 0.19 & 0.30 & 0.18 & 0.28 & 0.06 & 0.41 \\
\hline Bacillus_niacini_g_Bacillus & 0.37 & 0.21 & 0.09 & 0.03 & 0.05 & 0.01 & 0.35 & 0.07 & 1.39 & 0.03 \\
\hline uncultured_Chloroflexi_bacterium_g_norank_o_JG30-KF-CM45 & 0.29 & 0.42 & 0.45 & 0.32 & 0.29 & 0.31 & 0.13 & 0.26 & 0.09 & 0.34 \\
\hline unclassified_g_RB41 & 0.28 & 0.73 & 0.42 & 0.13 & 0.33 & 0.44 & 0.10 & 0.16 & 0.04 & 0.27 \\
\hline unclassified_g_H16 & 0.30 & 0.46 & 0.34 & 0.27 & 0.23 & 0.24 & 0.16 & 0.28 & 0.13 & 0.44 \\
\hline unclassified_g_norank_f_Elev-16S-1332 & 0.36 & 0.40 & 0.36 & 0.30 & 0.36 & 0.27 & 0.13 & 0.21 & 0.11 & 0.36 \\
\hline Bacillus_vireti & 1.24 & 0.06 & 0.17 & 0.03 & 0.17 & 0.03 & .54 & 0.04 & 0.39 & 0.07 \\
\hline unclassified_g_Nocardioides & 0.38 & 0.58 & 0.33 & 0.31 & 0.21 & 0.26 & 0.11 & 0.20 & 0.09 & 0.36 \\
\hline unclassified_f_Intrasporangiaceae & 0.40 & 0.48 & 0.31 & 0.16 & 0.27 & 0.24 & 0.08 & 0.21 & 0.05 & 0.43 \\
\hline unclassified_g_norank_f_Gemmatimonadaceae & 0.35 & 0.34 & 0.24 & 0.20 & 0.27 & 0.23 & 0.17 & 0.23 & 0.13 & 0.39 \\
\hline unclassified_g_Steroidobacter & 0.38 & 0.35 & 0.22 & 0.21 & 0.35 & 0.43 & 0.10 & 0.15 & 0.08 & 0.26 \\
\hline unclassified_o_Bacillales & 0.53 & 0.17 & 0.02 & 0.01 & 0.01 & 0.00 & 0.85 & 0.39 & 0.26 & 0.01 \\
\hline uncultured_bacterium_g_norank_c_Gitt-GS-136 & 0.21 & 0.44 & 0.34 & 0.16 & 0.25 & 0.36 & 0.14 & 0.25 & 0.06 & 0.29 \\
\hline unclassified_f_Nocardioidaceae & 0.41 & 0.51 & 0.26 & 0.32 & 0.15 & 0.19 & 0.09 & 0.20 & 0.09 & 0.26 \\
\hline unclassified_g_norank_f_Anaerolineaceae & 0.21 & 0.50 & 0.34 & 0.14 & 0.23 & 0.26 & 0.11 & 0.26 & 0.06 & 0.27 \\
\hline
\end{tabular}


Table A2. Cont.

\begin{tabular}{|c|c|c|c|c|c|c|c|c|c|c|}
\hline \multirow[t]{2}{*}{ Bacterial Species Name } & \multicolumn{9}{|c|}{ Bacterial Species Abundance (\%) Per Sample } & \multirow[b]{2}{*}{ M2b } \\
\hline & CS & $\mathrm{Ni}$ & PEXa & PEXb & SIPXa & SIPXb & M1a & M1b & M2a & \\
\hline Agromyces_ulmi & 0.79 & 0.68 & 0.22 & 0.15 & 0.22 & 0.13 & 0.04 & 0.06 & 0.03 & 0.13 \\
\hline unclassified_g_norank_o_Xanthomonadales & 0.31 & 0.30 & 0.25 & 0.19 & 0.21 & 0.23 & 0.13 & 0.22 & 0.10 & 0.37 \\
\hline uncultured_Rubrobacterales_bacterium_g_Gaiella & 0.40 & 0.33 & 0.22 & 0.23 & 0.27 & 0.22 & 0.10 & 0.17 & 0.09 & 0.30 \\
\hline uncultured_soil_bacterium_g_norank_c_Actinobacteria & 0.24 & 0.34 & 0.27 & 0.12 & 0.31 & 0.24 & 0.20 & 0.22 & 0.05 & 0.27 \\
\hline unclassified_g_Brevibacillus & 0.12 & 0.28 & 0.02 & 0.01 & 0.03 & 0.01 & 0.57 & 0.18 & 0.58 & 0.21 \\
\hline uncultured_Gemmatimonadales_bacterium_g_norank & 0.30 & 0.29 & 0.21 & 0.20 & 0.24 & 0.18 & 0.13 & 0.25 & 0.09 & 0.36 \\
\hline uncultured_bacterium_g_norank_o_JG30-KF-CM45 & 0.28 & 0.43 & 0.29 & 0.28 & 0.18 & 0.24 & 0.07 & 0.19 & 0.06 & 0.23 \\
\hline unclassified_g_norank_o_Acidimicrobiales & 0.33 & 0.30 & 0.25 & 0.26 & 0.22 & 0.19 & 0.10 & 0.17 & 0.09 & 0.33 \\
\hline unclassified_g_Microlunatus & 0.32 & 0.28 & 0.25 & 0.25 & 0.29 & 0.20 & 0.09 & 0.16 & 0.09 & 0.30 \\
\hline uncultured_actinobacterium_g_norank & 0.32 & 0.29 & 0.25 & 0.24 & 0.24 & 0.16 & 0.09 & 0.16 & 0.08 & 0.32 \\
\hline unclassified_g_Achromobacter & 0.06 & 0.01 & 0.47 & 1.08 & 0.09 & 0.14 & 0.09 & 0.11 & 0.04 & 0.10 \\
\hline uncultured_Burkholderiales_bacterium_g_norank_f_Nitrosomonadaceae & 0.25 & 0.31 & 0.19 & 0.19 & 0.26 & 0.16 & 0.10 & 0.22 & 0.08 & 0.31 \\
\hline uncultured_Acidobacteria_bacterium_g_norank_c_Acidobacteria & 0.27 & 0.39 & 0.31 & 0.09 & 0.12 & 0.21 & 0.10 & 0.17 & 0.03 & 0.32 \\
\hline uncultured_bacterium_g_norank_f_288-2 & 0.32 & 0.25 & 0.26 & 0.21 & 0.24 & 0.17 & 0.07 & 0.15 & 0.08 & 0.26 \\
\hline unclassified_f_Comamonadaceae & 0.32 & 0.32 & 0.15 & 0.15 & 0.21 & 0.19 & 0.07 & 0.18 & 0.06 & 0.24 \\
\hline unclassified_g_Mycobacterium & 0.26 & 0.28 & 0.19 & 0.18 & 0.24 & 0.15 & 0.09 & 0.14 & 0.06 & 0.20 \\
\hline uncultured_Rhodoplanes_sp._g_Variibacter & 0.28 & 0.25 & 0.13 & 0.16 & 0.18 & 0.17 & 0.10 & 0.16 & 0.08 & 0.26 \\
\hline Rhizobium_giardinii_g_Rhizobium & 0.11 & 0.09 & 0.45 & 0.45 & 0.29 & 0.26 & 0.02 & 0.06 & 0.02 & 0.07 \\
\hline unclassified_g_norank_c_TK10 & 0.23 & 0.30 & 0.22 & 0.16 & 0.19 & 0.19 & 0.07 & 0.15 & 0.05 & 0.19 \\
\hline Azotobacter_beijerinckii & 0.04 & 0.00 & 0.32 & 0.25 & 0.40 & 0.46 & 0.06 & 0.12 & 0.02 & 0.01 \\
\hline uncultured_Actinomycetales_bacterium_g_norank_f_OM1_clade & 0.19 & 0.22 & 0.18 & 0.15 & 0.14 & 0.12 & 0.09 & 0.18 & 0.08 & 0.27 \\
\hline Agromyces_indicus & 0.69 & 0.78 & 0.04 & 0.04 & 0.06 & 0.04 & .00 & 0.01 & 0.00 & 0.03 \\
\hline Variovorax_soli & 0.12 & 0.10 & 0.16 & 0.08 & 0.60 & 0.38 & 0.04 & 0.07 & 0.01 & 0.05 \\
\hline unclassified_g_norank_c_KD4-96 & 0.17 & 0.28 & 0.22 & 0.09 & 0.17 & 0.16 & 0.07 & 0.17 & 0.04 & 0.18 \\
\hline unclassified_g_Iamia & 0.23 & 0.20 & 0.16 & 0.18 & 0.15 & 0.15 & 0.06 & 0.14 & 0.06 & 0.22 \\
\hline uncultured_Thermomonas_sp._g_Lysobacter & 0.62 & 0.11 & 0.06 & 0.05 & 0.31 & 0.31 & 0.02 & 0.03 & 0.01 & 0.07 \\
\hline uncultured_bacterium_g_norank_f_Intrasporangiaceae & 0.44 & 0.34 & 0.14 & 0.10 & 0.13 & 0.10 & 0.05 & 0.07 & 0.04 & 0.13 \\
\hline uncultured_bacterium_g_norank_o_Gaiellales & 0.21 & 0.17 & 0.18 & 0.15 & 0.15 & 0.12 & 0.06 & 0.13 & 0.07 & 0.25 \\
\hline uncultured_Beijerinckiaceae_bacterium_g_Microvirga & 0.20 & 0.19 & 0.16 & 0.16 & 0.14 & 0.15 & 0.06 & 0.15 & 0.06 & 0.21 \\
\hline uncultured_actinobacterium_g_Micromonospora & 0.21 & 0.21 & 0.18 & 0.15 & 0.11 & 0.13 & 0.07 & 0.14 & 0.06 & 0.19 \\
\hline Lysobacter_yangpyeongensis & 0.57 & 0.01 & 0.07 & 0.01 & 0.61 & 0.14 & 0.03 & 0.00 & 0.05 & 0.02 \\
\hline
\end{tabular}


Table A2. Cont.

\begin{tabular}{|c|c|c|c|c|c|c|c|c|c|c|}
\hline \multirow[t]{2}{*}{ Bacterial Species Name } & \multicolumn{9}{|c|}{ Bacterial Species Abundance (\%) Per Sample } & \multirow[b]{2}{*}{$\mathrm{M} 2 \mathrm{~b}$} \\
\hline & CS & $\mathrm{Ni}$ & PEXa & PEXb & SIPXa & SIPXb & M1a & M1b & M2a & \\
\hline Micromonospora_chokoriensis & 0.15 & 0.14 & 0.18 & 0.15 & 0.15 & 0.10 & 0.10 & 0.20 & 0.07 & 0.21 \\
\hline uncultured_Actinomycetales_bacterium_g_norank_c_Actinobacteria & 0.12 & 0.21 & 0.19 & 0.09 & 0.18 & 0.17 & 0.12 & 0.14 & 0.03 & 0.20 \\
\hline unclassified_g_norank_f_Xanthomonadales_Incertae_Sedis & 0.27 & 0.22 & 0.10 & 0.08 & 0.20 & 0.16 & 0.05 & 0.12 & 0.04 & 0.21 \\
\hline uncultured_bacterium_g_Candidatus_Xiphinematobacter & 0.08 & 0.31 & 0.14 & 0.04 & 0.06 & 0.16 & 0.11 & 0.22 & 0.02 & 0.25 \\
\hline unclassified_g_Lysinibacillus & 0.59 & 0.00 & 0.03 & 0.02 & 0.02 & 0.00 & 0.22 & 0.08 & 0.35 & 0.03 \\
\hline uncultured_proteobacterium_g_Acidibacter & 0.18 & 0.24 & 0.14 & 0.12 & 0.14 & 0.18 & 0.07 & 0.09 & 0.06 & 0.17 \\
\hline uncultured_bacterium_g_Ilumatobacter & 0.21 & 0.19 & 0.14 & 0.16 & 0.15 & 0.12 & 0.06 & 0.11 & 0.06 & 0.18 \\
\hline Sphingomonas_leidyi & 0.31 & 0.12 & 0.08 & 0.10 & 0.30 & 0.27 & 0.04 & 0.06 & 0.03 & 0.10 \\
\hline bacterium_WX65 & 0.26 & 0.20 & 0.16 & 0.16 & 0.10 & 0.13 & 0.04 & 0.13 & 0.04 & 0.16 \\
\hline uncultured_Pseudoxanthomonas_sp._g_norank & 0.19 & 0.18 & 0.12 & 0.12 & 0.14 & 0.12 & 0.08 & 0.13 & 0.07 & 0.21 \\
\hline unclassified_g_norank_f_Rhodobiaceae & 0.17 & 0.16 & 0.12 & 0.14 & 0.14 & 0.10 & 0.08 & 0.13 & 0.07 & 0.22 \\
\hline Nocardioides_terrigena & 0.16 & 0.31 & 0.13 & 0.17 & 0.07 & 0.11 & 0.04 & 0.10 & 0.07 & 0.18 \\
\hline unclassified_g_Bradyrhizobium & 0.27 & 0.25 & 0.07 & 0.05 & 0.18 & 0.12 & .06 & 0.10 & 0.04 & 0.18 \\
\hline unclassified_g_norank_f_Alcaligenaceae & 0.23 & 0.22 & 0.13 & 0.12 & 0.16 & 0.12 & 0.04 & 0.09 & 0.04 & 0.17 \\
\hline uncultured_bacterium_g_norank_o_SC-I-84 & 0.25 & 0.15 & 0.11 & 0.09 & 0.12 & 0.10 & 0.06 & 0.15 & 0.03 & 0.24 \\
\hline Acidobacteria_bacterium_CB_286306 & 0.15 & 0.29 & 0.21 & 0.05 & 0.10 & 0.14 & 0.06 & 0.12 & 0.04 & 0.14 \\
\hline unclassified_g_Gracilibacillus & 0.01 & 0.08 & 0.01 & - & 0.00 & 0.00 & 0.17 & 0.00 & 0.69 & 0.09 \\
\hline unclassified_k_norank & 0.12 & 0.21 & 0.14 & 0.10 & 0.12 & 0.13 & 0.07 & 0.14 & 0.03 & 0.16 \\
\hline Bacillus_litoralis_g_Bacillus & 0.85 & .04 & 0.05 & 0.05 & 0.04 & 0.03 & 0.10 & 0.03 & 0.02 & 0.06 \\
\hline unclassified_g_Streptococcus & 0.01 & 0.01 & 0.00 & 0.00 & 0.00 & 0.21 & 0.33 & 0.22 & 0.10 & 0.20 \\
\hline Massilia_timonae & 0.06 & 0.03 & 0.07 & 0.08 & 0.51 & 0.38 & 0.03 & 0.01 & 0.01 & 0.02 \\
\hline unclassified_g_norank_f_fAcidimicrobiaceae & 0.17 & 0.16 & 0.13 & 0.12 & 0.10 & 0.08 & 0.05 & 0.10 & 0.04 & 0.21 \\
\hline Agrococcus_jenensis & 0.11 & 0.43 & 0.11 & 0.08 & 0.10 & 0.09 & 0.03 & 0.07 & 0.03 & 0.12 \\
\hline uncultured_bacterium_g_Microlunatus & 0.24 & 0.21 & 0.14 & 0.09 & 0.13 & 0.12 & 0.04 & 0.05 & 0.03 & 0.12 \\
\hline unclassified_g_Ramlibacter & 0.26 & 0.14 & 0.10 & 0.05 & 0.16 & 0.11 & 0.06 & 0.09 & 0.03 & 0.14 \\
\hline uncultured_Chloroflexi_bacterium_g_norank_c_KD4-96 & 0.13 & 0.21 & 0.14 & 0.09 & 0.10 & 0.14 & 0.05 & 0.10 & 0.03 & 0.14 \\
\hline unclassified_g_Blastococcus & 0.28 & 0.15 & 0.12 & 0.11 & 0.10 & 0.12 & 0.03 & 0.07 & 0.05 & 0.10 \\
\hline uncultured_Rhodobiaceae_bacterium_g_norank_f_Rhodobiaceae & 0.14 & 0.13 & 0.11 & 0.10 & 0.12 & 0.07 & 0.08 & 0.14 & 0.05 & 0.18 \\
\hline unclassified_g_Massilia & 0.02 & 0.02 & 0.15 & 0.13 & 0.39 & 0.25 & 0.08 & 0.00 & 0.01 & 0.08 \\
\hline uncultured_bacterium_g_norank_f_Elev-16S-1332 & 0.16 & 0.16 & 0.12 & 0.12 & 0.13 & 0.09 & 0.04 & 0.06 & 0.04 & 0.19 \\
\hline
\end{tabular}


Table A2. Cont.

\begin{tabular}{|c|c|c|c|c|c|c|c|c|c|c|}
\hline \multirow[t]{2}{*}{ Bacterial Species Name } & \multicolumn{9}{|c|}{ Bacterial Species Abundance (\%) Per Sample } & \multirow[b]{2}{*}{ M2b } \\
\hline & CS & $\mathrm{Ni}$ & PEXa & PEXb & SIPXa & SIPXb & M1a & M1b & M2a & \\
\hline uncultured_bacterium_g_Roseiflexus & 0.19 & 0.17 & 0.14 & 0.13 & 0.14 & 0.11 & 0.02 & 0.06 & 0.03 & 0.11 \\
\hline unclassified_g_Candidatus_Alysiosphaera & 0.18 & 0.17 & 0.16 & 0.13 & 0.09 & 0.09 & 0.03 & 0.06 & 0.04 & 0.13 \\
\hline Solibacillus_silvestris_StLB046 & 0.04 & - & 0.00 & 0.01 & 0.00 & - & 0.67 & 0.12 & 0.02 & 0.00 \\
\hline uncultured_soil_bacterium_g_norank_c_S085 & 0.13 & 0.15 & 0.12 & 0.09 & 0.08 & 0.11 & 0.07 & 0.10 & 0.04 & 0.14 \\
\hline unclassified_g_Roseiflexus & 0.11 & 0.17 & 0.15 & 0.12 & 0.12 & 0.12 & 0.03 & 0.08 & 0.03 & 0.09 \\
\hline Bacillus_humi & 0.23 & 0.02 & 0.01 & 0.02 & 0.01 & 0.00 & 0.43 & 0.04 & 0.11 & 0.02 \\
\hline Acidobacteria_bacterium_LWH4 & 0.21 & 0.24 & 0.12 & 0.03 & 0.07 & 0.15 & 0.05 & 0.04 & 0.01 & 0.09 \\
\hline uncultured_bacterium_g_Chryseolinea & 0.09 & 0.19 & 0.12 & 0.16 & 0.06 & 0.08 & 0.02 & 0.08 & 0.03 & 0.18 \\
\hline unclassified_f_Oxalobacteraceae & 0.04 & 0.01 & 0.28 & 0.05 & 0.29 & 0.24 & 0.01 & 0.03 & 0.01 & 0.03 \\
\hline unclassified_f_Rhodobacteraceae & 0.22 & 0.11 & 0.10 & 0.09 & 0.10 & 0.09 & 0.05 & 0.06 & 0.03 & 0.13 \\
\hline uncultured_bacterium_g_norank_f_0319-6M6 & 0.15 & 0.12 & 0.09 & 0.11 & 0.09 & 0.08 & 0.04 & 0.09 & 0.03 & 0.13 \\
\hline unclassified_g_norank_o_TRA-20 & 0.13 & 0.14 & 0.09 & 0.09 & 0.08 & 0.08 & 0.04 & 0.11 & 0.02 & 0.11 \\
\hline uncultured_bacterium_g_G55 & 0.12 & 0.13 & 0.12 & 0.10 & 0.09 & 0.10 & 0.05 & 0.06 & 0.04 & 0.11 \\
\hline unclassified_g_norank_o_AKYG1722 & 0.13 & 0.15 & 0.13 & 0.12 & 0.07 & 0.08 & 0.04 & 0.07 & 0.04 & 0.07 \\
\hline uncultured_soil_bacterium_g_norank_f_Caldilineaceae & 0.14 & 0.09 & 0.14 & 0.07 & 0.08 & 0.09 & 0.05 & 0.08 & 0.03 & 0.10 \\
\hline unclassified_g_Pantoea & 0.03 & - & 0.14 & 0.40 & 0.11 & 0.17 & 0.01 & 0.03 & - & 0.01 \\
\hline uncultured_Burkholderiaceae_bacterium_g_norank_f_Nitrosomonadaceae & 0.10 & 0.15 & 0.09 & 0.06 & 0.10 & 0.06 & 0.04 & 0.09 & 0.04 & 0.11 \\
\hline unclassified_g_norank_f_Cytophagaceae & 0.11 & 0.22 & 0.08 & 0.06 & 0.05 & 0.06 & 0.02 & 0.09 & 0.04 & 0.12 \\
\hline uncultured_bacterium_g_norank_p_Tectomicrobia & 0.15 & 0.15 & 0.13 & 0.07 & 0.08 & 0.10 & 0.03 & 0.04 & 0.02 & 0.08 \\
\hline uncultured_bacterium_g_Ammoniphilus & 0.07 & 0.02 & 0.04 & 0.01 & 0.01 & 0.01 & 0.29 & 0.21 & 0.08 & 0.01 \\
\hline uncultured_Acidobacteria_bacterium_g_norank_f_Blastocatellaceae_Subgroup_4_ & 0.20 & 0.17 & 0.05 & 0.03 & 0.06 & 0.08 & 0.04 & 0.08 & 0.01 & 0.14 \\
\hline Cellulomonas_fimi & 0.15 & 0.37 & 0.06 & 0.03 & 0.06 & 0.04 & 0.01 & 0.03 & 0.02 & 0.05 \\
\hline unclassified_g_Pedomicrobium & 0.13 & 0.09 & 0.07 & 0.08 & 0.08 & 0.06 & 0.04 & 0.08 & 0.04 & 0.12 \\
\hline uncultured_Caulobacteraceae_bacterium_g_Phenylobacterium & 0.04 & 0.01 & 0.22 & 0.06 & 0.27 & 0.13 & 0.01 & 0.02 & 0.01 & 0.03 \\
\hline unclassified_g_Solirubrobacter & 0.19 & 0.14 & 0.09 & 0.08 & 0.07 & 0.09 & 0.02 & 0.06 & 0.02 & 0.04 \\
\hline uncultured_bacterium_g_norank_o_Acidimicrobiales & 0.15 & 0.11 & 0.08 & 0.09 & 0.07 & 0.06 & 0.03 & 0.08 & 0.03 & 0.10 \\
\hline uncultured_bacterium_g_Phenylobacterium & 0.15 & 0.08 & 0.06 & 0.05 & 0.15 & 0.12 & 0.02 & 0.06 & 0.02 & 0.07 \\
\hline uncultured_Hyphomicrobiaceae_bacterium_g_Hyphomicrobium & 0.10 & 0.08 & 0.07 & 0.07 & 0.07 & 0.06 & 0.04 & 0.08 & 0.04 & 0.14 \\
\hline unclassified_g_Cellulomonas & 0.14 & 0.38 & 0.06 & 0.02 & 0.05 & 0.04 & 0.01 & 0.01 & 0.01 & 0.04 \\
\hline Nocardioides_exalbidus & 0.06 & 0.22 & 0.07 & 0.09 & 0.07 & 0.07 & 0.02 & 0.03 & 0.02 & 0.08 \\
\hline
\end{tabular}


Table A2. Cont.

\begin{tabular}{|c|c|c|c|c|c|c|c|c|c|c|}
\hline \multirow[t]{2}{*}{ Bacterial Species Name } & \multicolumn{9}{|c|}{ Bacterial Species Abundance (\%) Per Sample } & \multirow[b]{2}{*}{ M2b } \\
\hline & CS & $\mathrm{Ni}$ & PEXa & PEXb & SIPXa & SIPXb & M1a & M1b & M2a & \\
\hline Paenibacillus_sp._Y412MC10 & 0.01 & 0.07 & 0.17 & 0.11 & 0.13 & 0.02 & 0.03 & 0.03 & 0.12 & 0.01 \\
\hline uncultured_Actinomycetales_bacterium_g_Rubrobacter & 0.15 & 0.07 & 0.10 & 0.06 & 0.06 & 0.07 & 0.03 & 0.06 & 0.03 & 0.09 \\
\hline uncultured_Geoalkalibacter_sp._g_norank_c_Acidobacteria & 0.08 & 0.11 & 0.11 & 0.05 & 0.04 & 0.07 & 0.05 & 0.09 & 0.02 & 0.09 \\
\hline uncultured_bacterium_gp 6 & 0.08 & 0.13 & 0.08 & 0.03 & 0.08 & 0.07 & 0.04 & 0.07 & 0.01 & 0.11 \\
\hline uncultured_candidate_division_SPAM_bacterium & 0.12 & 0.14 & 0.07 & 0.05 & 0.05 & 0.06 & 0.03 & 0.07 & 0.03 & 0.08 \\
\hline unclassified_g_Phyllobacterium & 0.06 & .09 & 0.10 & 0.14 & 0.07 & 0.10 & .03 & 0.04 & 0.02 & 0.04 \\
\hline unclassified_g_Arenimonas & 0.39 & 0.09 & 0.02 & 0.03 & 0.04 & 0.04 & .01 & 0.03 & 0.02 & 0.06 \\
\hline unclassified_g_norank_c_JG30-KF-CM66 & 0.09 & 0.10 & 0.09 & 0.06 & 0.07 & 0.06 & 0.04 & 0.04 & 0.02 & 0.10 \\
\hline unclassified_f_Propionibacteriaceae & 0.11 & 0.11 & 0.07 & 0.08 & 0.07 & 0.06 & 0.03 & 0.06 & 0.02 & 0.08 \\
\hline unclassified_g_Pseudonocardia & 0.11 & 0.07 & 0.06 & 0.05 & 0.08 & 0.06 & 0.04 & 0.07 & 0.04 & 0.09 \\
\hline unclassified_g_Microbispora & 0.06 & 0.05 & 0.08 & 0.07 & 0.08 & 0.05 & 0.04 & 0.09 & 0.03 & 0.12 \\
\hline uncultured_Acidimicrobidae_bacterium_g_norank_o_Acidimicrobiale & 0.11 & 0.10 & 0.07 & 0.06 & 0.07 & 0.08 & 0.02 & 0.04 & 0.03 & 0.09 \\
\hline unclassified_g_norank_f_Ellin6055 & 0.23 & 0.10 & 0.05 & 0.07 & 0.08 & 0.06 & 0.01 & 0.03 & 0.02 & 0.05 \\
\hline unclassified_g_Rubrobacter & 0.05 & 0.09 & 0.11 & 0.04 & 0.10 & 0.08 & 0.03 & 0.05 & 0.01 & 0.08 \\
\hline unclassified_g_Cronobacter & 0.02 & 0.17 & 0.15 & 0.22 & 0.16 & 0.12 & 0.01 & 0.01 & - & - \\
\hline uncultured_bacterium_g_norank_f_Planctomycetaceae & 0.06 & 0.09 & 0.07 & 0.03 & 0.05 & 0.06 & 0.05 & 0.06 & 0.01 & 0.08 \\
\hline uncultured_bacterium_g_Candidatus_Alysiosphaera & 0.08 & - & 0.12 & 0.08 & 0.06 & 0.06 & 0.02 & 0.03 & 0.03 & 0.07 \\
\hline Rhizobium_pusense & 0.06 & 0.02 & 0.13 & 0.16 & 0.14 & 0.12 & 0.01 & 0.01 & 0.00 & 0.00 \\
\hline Lysobacter_daejeonensis & 0.54 & 0.00 & .00 & 0.00 & 0.06 & 0.07 & 0.00 & 0.00 & 0.00 & 0.00 \\
\hline unclassified_o_Acidimicrobiales & 0.10 & 0.09 & 0.08 & 0.06 & 0.06 & 0.05 & 0.03 & 0.04 & 0.02 & 0.10 \\
\hline Agromyces_ramosus & 0.13 & 0.18 & 0.07 & 0.05 & 0.06 & 0.04 & 0.01 & 0.03 & 0.01 & 0.04 \\
\hline unclassified_f_Pseudomonadaceae & 0.35 & 0.00 & 0.00 & 0.03 & 0.05 & 0.02 & 0.00 & 0.11 & 0.06 & 0.01 \\
\hline uncultured_bacterium_g_Amaricoccus & 0.12 & 0.08 & 0.06 & 0.06 & 0.09 & 0.06 & 0.03 & 0.05 & 0.01 & 0.07 \\
\hline unclassified_g_norank_f_OM1_clade & 0.06 & 0.08 & 0.05 & 0.07 & 0.06 & 0.06 & 0.04 & 0.06 & 0.03 & 0.10 \\
\hline uncultured_bacterium_g_Methylibium & 0.09 & 0.05 & 0.12 & 0.06 & 0.11 & 0.10 & 0.02 & 0.02 & 0.01 & 0.05 \\
\hline uncultured_bacterium_g_Vicinamibacter & 0.11 & 0.13 & 0.06 & 0.01 & 0.08 & 0.07 & 0.02 & 0.04 & 0.02 & 0.07 \\
\hline unclassified_g_Paracoccus & 0.08 & 0.05 & 0.06 & 0.05 & 0.17 & 0.16 & 0.00 & 0.03 & 0.00 & 0.01 \\
\hline uncultured_Bacteroidetes_bacterium_g_norank_f_Chitinophagaceae & 0.18 & 0.14 & 0.05 & 0.04 & 0.05 & 0.03 & 0.00 & 0.03 & 0.02 & 0.06 \\
\hline Sphingobacterium_sp._21 & 0.02 & 0.55 & 0.00 & - & 0.01 & 0.01 & - & - & 0.00 & - \\
\hline wastewater_metagenome_g_norank_c_Acidobacteria & 0.08 & 0.13 & 0.07 & 0.03 & 0.06 & 0.06 & 0.02 & 0.06 & 0.01 & 0.07 \\
\hline unclassified_f_Micromonosporaceae & 0.06 & 0.06 & 0.05 & 0.06 & 0.06 & 0.04 & 0.04 & 0.07 & 0.03 & 0.11 \\
\hline
\end{tabular}


Table A2. Cont.

\begin{tabular}{|c|c|c|c|c|c|c|c|c|c|c|}
\hline \multirow[t]{2}{*}{ Bacterial Species Name } & \multicolumn{9}{|c|}{ Bacterial Species Abundance (\%) Per Sample } & \multirow[b]{2}{*}{ M2b } \\
\hline & CS & $\mathrm{Ni}$ & PEXa & PEXb & SIPXa & SIPXb & M1a & M1b & M2a & \\
\hline uncultured_Sedimentibacter_sp._g_Sedimentibacter & 0.62 & 0.00 & 0.00 & 0.00 & 0.00 & 0.00 & - & 0.00 & - & 0.00 \\
\hline Sporosarcina_luteola & 0.07 & 0.01 & 0.02 & 0.02 & 0.01 & 0.00 & 0.26 & 0.07 & 0.03 & 0.01 \\
\hline uncultured_bacterium_g_norank_f_Bradyrhizobiaceae & 0.10 & 0.07 & 0.03 & 0.03 & 0.07 & 0.05 & 0.03 & 0.05 & 0.03 & 0.09 \\
\hline unclassified_g_Altererythrobacter & 0.14 & 0.08 & 0.05 & 0.05 & 0.08 & 0.06 & 0.02 & 0.03 & 0.01 & 0.04 \\
\hline unclassified_g_Rhodococcus & 0.11 & 0.11 & 0.03 & 0.02 & 0.08 & 0.04 & 0.05 & 0.02 & 0.03 & 0.05 \\
\hline Microvirga_sp._JC119 & 0.08 & 0.02 & 0.16 & 0.03 & 0.12 & 0.06 & 0.02 & 0.01 & 0.01 & 0.02 \\
\hline uncultured_Burkholderiales_bacterium_g_norank_o_SC-I-84 & 0.11 & 0.07 & 0.04 & 0.05 & 0.04 & 0.02 & 0.02 & 0.06 & 0.02 & 0.09 \\
\hline uncultured_bacterium_g_norank_f_BIrii41 & 0.11 & 0.11 & 0.05 & 0.03 & 0.06 & 0.03 & 0.03 & 0.03 & 0.02 & 0.04 \\
\hline Acidobacteria_bacterium_CB_286339 & 0.06 & 0.11 & 0.08 & 0.02 & 0.04 & 0.07 & 0.02 & 0.03 & 0.01 & 0.03 \\
\hline uncultured_bacterium_g_Paenisporosarcina & 0.17 & 0.02 & 0.03 & 0.03 & 0.02 & 0.01 & 0.05 & 0.06 & 0.03 & 0.05 \\
\hline Paenibacillus_glycanilyticus & 0.17 & 0.01 & 0.05 & 0.01 & 0.14 & 0.01 & 0.02 & 0.02 & 0.01 & 0.04 \\
\hline uncultured_soil_bacterium_g_Adhaeribacter & 0.13 & 0.11 & 0.04 & 0.04 & 0.03 & 0.02 & 0.02 & 0.03 & 0.02 & 0.05 \\
\hline unclassified_f_Archangiaceae & 0.09 & 0.12 & 0.07 & 0.02 & 0.06 & 0.04 & 0.01 & 0.01 & 0.02 & 0.03 \\
\hline unclassified_g_norank_f_Sporichthyaceae & 0.13 & 0.07 & 0.03 & 0.04 & 0.03 & 0.04 & 0.01 & 0.03 & 0.02 & 0.06 \\
\hline Brevundimonas_alba & 0.06 & 0.02 & 0.02 & 0.01 & 0.17 & 0.11 & 0.01 & 0.02 & 0.01 & 0.03 \\
\hline Acinetobacter_schindleri & 0.00 & 0.00 & 0.00 & - & 0.01 & 0.08 & 0.00 & 0.01 & 0.27 & - \\
\hline uncultured_actinobacterium_g_Nocardioides & 0.07 & 0.11 & 0.04 & 0.04 & 0.04 & 0.03 & 0.01 & 0.02 & 0.03 & 0.04 \\
\hline Arthrobacter_crystallopoietes & 0.02 & 0.35 & 0.01 & - & 0.02 & 0.00 & - & 0.01 & 0.00 & 0.01 \\
\hline uncultured_bacterium_g_Geodermatophilus & 0.10 & 0.05 & 0.06 & 0.04 & 0.04 & 0.04 & 0.01 & 0.03 & 0.01 & 0.04 \\
\hline uncultured_bacterium_g_Stenotrophobacter & 0.11 & 0.06 & 0.03 & 0.01 & 0.03 & 0.04 & 0.02 & 0.03 & 0.01 & 0.06 \\
\hline unclassified_g_Exiguobacterium & 0.02 & - & 0.00 & 0.10 & 0.00 & 0.05 & - & - & 0.17 & 0.08 \\
\hline uncultured_Acidobacteriaceae_bacterium_g_RB41 & 0.05 & 0.11 & 0.05 & 0.01 & 0.04 & - & 0.01 & 0.03 & 0.01 & 0.03 \\
\hline Pseudoxanthomonas_mexicana & 0.03 & 0.00 & 0.02 & 0.00 & 0.05 & 0.05 & 0.00 & 0.00 & 0.02 & 0.18 \\
\hline unclassified_g_Flavobacterium & 0.02 & 0.02 & 0.03 & 0.03 & 0.11 & 0.04 & 0.02 & 0.02 & 0.01 & 0.03 \\
\hline Georgenia_muralis & 0.07 & 0.20 & 0.01 & 0.00 & 0.01 & 0.00 & 0.00 & 0.01 & 0.00 & 0.02 \\
\hline Nocardioides_oleivorans & 0.04 & 0.14 & 0.03 & 0.03 & 0.01 & 0.01 & 0.01 & 0.01 & 0.01 & 0.02 \\
\hline unclassified_g_Sphingobacterium & 0.01 & 0.01 & 0.01 & - & 0.14 & 0.09 & - & 0.01 & 0.03 & 0.01 \\
\hline uncultured_bacterium_g_norank_f_Xanthomonadaceae & 0.10 & 0.04 & 0.02 & 0.01 & 0.03 & 0.02 & 0.01 & 0.03 & 0.01 & 0.04 \\
\hline Lechevalieria_aerocolonigenes_g_Lechevalieria & 0.03 & 0.20 & 0.02 & 0.00 & 0.02 & 0.02 & 0.00 & 0.01 & 0.00 & 0.01 \\
\hline unclassified_g_Leucobacter & 0.00 & 0.28 & 0.00 & - & - & - & - & 0.00 & - & - \\
\hline uncultured_Firmicutes_bacterium_g_Paenibacillus & 0.13 & 0.00 & 0.06 & 0.01 & 0.02 & 0.00 & 0.04 & 0.00 & - & 0.01 \\
\hline
\end{tabular}


Table A2. Cont.

\begin{tabular}{|c|c|c|c|c|c|c|c|c|c|c|}
\hline \multirow[t]{2}{*}{ Bacterial Species Name } & \multicolumn{9}{|c|}{ Bacterial Species Abundance (\%) Per Sample } & \multirow[b]{2}{*}{ M2b } \\
\hline & CS & $\mathrm{Ni}$ & PEXa & PEXb & SIPXa & SIPXb & M1a & M1b & M2a & \\
\hline Clostridium_sp._SW002 & 0.26 & - & 0.01 & - & 0.00 & - & - & - & - & - \\
\hline Paenibacillus_timonensis & 0.14 & 0.00 & 0.04 & 0.04 & 0.02 & 0.00 & - & 0.00 & 0.01 & 0.00 \\
\hline Brachybacterium_phenoliresistens & 0.01 & 0.22 & - & 0.00 & - & - & - & - & - & - \\
\hline uncultured_bacterium_g_Fonticella & 0.23 & - & 0.00 & - & - & - & 0.00 & - & 0.00 & 0.00 \\
\hline Paenibacillus_harenae & 0.05 & 0.01 & 0.10 & 0.01 & 0.01 & 0.00 & 0.01 & 0.01 & 0.00 & 0.00 \\
\hline uncultured_bacterium_g_Clostridium_sensu_stricto_7 & 0.23 & - & - & - & - & - & - & - & 0.00 & - \\
\hline unclassified_g_Clostridium_sensu_stricto_7 & 0.21 & - & - & - & 0.00 & 0.00 & - & - & - & - \\
\hline unclassified_g_Cohnella & 0.10 & 0.01 & 0.03 & 0.00 & 0.01 & 0.00 & 0.01 & 0.01 & 0.00 & 0.01 \\
\hline Clostridiaceae_bacterium_mt10 & 0.15 & - & - & - & 0.00 & - & - & 0.00 & - & - \\
\hline Ureibacillus_thermosphaericus & 0.12 & - & - & 0.00 & 0.00 & 0.00 & 0.00 & - & - & 0.00 \\
\hline Clostridium_polyendosporum & 0.12 & - & 0.01 & 0.00 & 0.00 & - & - & 0.00 & - & - \\
\hline unclassified_g_Ruminiclostridium_1 & 0.10 & - & 0.00 & - & 0.00 & - & - & 0.00 & - & 0.00 \\
\hline Massilia_dura & - & 0.00 & 0.05 & 0.12 & 0.02 & 0.02 & 0.00 & 0.00 & 0.00 & 0.01 \\
\hline [Pseudomonas]_hibiscicola & - & 0.00 & 0.02 & 0.04 & 0.05 & 0.01 & 0.06 & 0.00 & 0.07 & 0.26 \\
\hline unclassified_g_Neochlamydia & - & - & - & 0.26 & 0.01 & 0.00 & - & - & - & - \\
\hline others & 13.4 & 13.7 & 10.1 & 8.02 & 8.85 & 8.60 & 4.14 & 7.22 & 3.13 & 11.46 \\
\hline
\end{tabular}

The empty cells (-) indicate that the corresponding bacterial specie is absent or is less than $0.1 \%$ abundant in the corresponding sample. 


\section{References}

1. Dixit, R.; Malaviya, D.; Pandiyan, K.; Singh, U.; Sahu, A.; Shukla, R.; Singh, B.; Rai, J.; Sharma, P.; Lade, H. Bioremediation of heavy metals from soil and aquatic environment: An overview of principles and criteria of fundamental processes. Sustainability 2015, 7, 2189-2212. [CrossRef]

2. Rong, X.-M.; Huang, Q.-Y.; Jiang, D.-H.; Cai, P.; Liang, W. Isothermal Microcalorimetry: A Review of Applications in Soil and Environmental Sciences. Pedosphere 2007, 17, 137-145. [CrossRef]

3. Gadd, G.M. Metals, minerals and microbes: Geomicrobiology and bioremediation. Microbiology 2010, 156, 609-643. [CrossRef] [PubMed]

4. Chakraborty, S.; Saha, N.; Roy, S.S. Role of microbes in soil formation and aggregation. Innov. Farm. 2016, 1, 11-14.

5. Aislabie, J.; Deslippe, J.R.; Dymond, J. Soil microbes and their contribution to soil services. In Ecosystem Services in New Zealand-Conditions and Trends; Manaaki Whenua Press: Lincoln, New Zealand, 2013; pp. 143-161.

6. Harasim, P.; Filipek, T.; Harasim, P. Nickel in the environment. J. Elem. 2015. [CrossRef]

7. Ngole, V.; Ekosse, G. Copper, nickel and zinc contamination in soils within the precincts of mining and landfilling environments. Int. J. Environ. Sci. Technol. 2012, 9, 485-494. [CrossRef]

8. Ahmad, M.S.A.; Ashraf, M. Essential roles and hazardous effects of nickel in plants. In Reviews of Environmental Contamination and Toxicology; Springer: Berlin, Germany, 2012; pp. 125-167.

9. Barałkiewicz, D.; Siepak, J. Chromium, nickel and cobalt in environmental samples and existing legal norms. Pol. J. Environ. Stud. 1999, 8, 201-208.

10. Bulatovic, S.M. Handbook of Flotation Reagents: Chemistry, Theory and Practice: Volume 1: Flotation of Sulfide Ores; Elsevier: Amsterdam, The Netherlands, 2007.

11. Na, L.; Yong, C.; Chao, Z.; Wen, Z.; Fu, M.; Chen, W.; Song, W. Highly Sensitive Determination of Butyl Xanthate in Surface and Drinking Water by Headspace Gas Chromatography with Electron Capture Detector. Chromatographia 2015, 78, 1305-1310.

12. Pearse, M.J. An overview of the use of chemical reagents in mineral processing. Miner. Eng. 2005, 18, 139-149. [CrossRef]

13. Sicupira, L.; Veloso, T.; Reis, F.; Leão, V. Assessing metal recovery from low-grade copper ores containing fluoride. Hydrometallurgy 2011, 109, 202-210. [CrossRef]

14. Nicnas, S.E.X. Priority Existing Chemical. Secondary Notification Assessment, Report N5S; National Industrial Chemicals Notification and Assessment Scheme: Canberra, Australia, 2000; pp. 20-22.

15. Edraki, M.; Baumgartl, T.; Manlapig, E.; Bradshaw, D.; Franks, D.M.; Moran, C.J. Designing mine tailings for better environmental, social and economic outcomes: A review of alternative approaches. J. Clean. Prod. 2014, 84, 411-420. [CrossRef]

16. Antoniadis, V.; Shaheen, S.M.; Boersch, J.; Frohne, T.; Du Laing, G.; Rinklebe, J. Bioavailability and risk assessment of potentially toxic elements in garden edible vegetables and soils around a highly contaminated former mining area in Germany. J. Environ. Manag. 2017, 186, 192-200. [CrossRef] [PubMed]

17. Chen, C.Y.; Lin, T.H. Nickel toxicity to human term placenta: In vitro study on lipid peroxidation. J. Toxicol. Environ. Health Part A 1998, 54, 37-47.

18. Cempel, M.; Nikel, G. A Review of Its Sources and Environmental Toxicology. Pol. J. Environ. Stud. 2006, 15, 375-382.

19. Das, K.K.; Das, S.N.; Dhundasi, S.A. Nickel, its adverse health effects \& oxidative stress. Indian J. Med Res. 2008, 128, 412-425. [PubMed]

20. None, N. (Environmental Health Criteria 108). 383 Seiten, 36 Tab. World Health Organization, Geneva 1991. Preis: 38,- Sw.fr.; 34,20 US \$ (Entwicklungsländer 26,60 Sw.fr.). Food 1992, 36, 102.

21. Gad, N.; El-Sherif, M.; El-Gereedly, N. Influence of nickel on some physiological aspects of tomato plants. Aust. J. Basic Appl. Sci. 2007, 1, 286-293.

22. Rastogi, G.; Sani, R.K. Molecular Techniques to Assess Microbial Community Structure, Function, and Dynamics in the Environment. In Microbes and Microbial Technology; Springer: New York, NY, USA, 2011; pp. 29-57.

23. Wyszkowska, J.; Kucharski, J.; Boros, E. Effect of nickel contamination on soil enzymatic activities. Plant Soil Environ. 2005, 51, 523-531. [CrossRef] 
24. Ko, K.-S.; Ha, K.; Kong, I.C. Effects of monotypic and binary mixtures of metal oxide nanoparticles on microbial growth in sandy soil collected from artificial recharge sites. Int. J. Mol. Sci. 2015, 16, 27967-27977. [CrossRef] [PubMed]

25. Lokke, H.; Ragas, A.M.; Holmstrup, M. Tools and perspectives for assessing chemical mixtures and multiple stressors. Toxicology 2013, 313, 73-82. [CrossRef] [PubMed]

26. McCarty, L.; Borgert, C. Review of the toxicity of chemical mixtures: Theory, policy, and regulatory practice. Regul. Toxicol. Pharmacol. 2006, 45, 119-143. [CrossRef] [PubMed]

27. Downing, H.F.; Delorenzo, M.E.; Fulton, M.H.; Scott, G.I.; Madden, C.J.; Kucklick, J.R. Effects of the Agricultural Pesticides Atrazine, Chlorothalonil, and Endosulfan on South Florida Microbial Assemblages. Ecotoxicology 2004, 13, 245-260. [CrossRef] [PubMed]

28. Muturi, E.J.; Donthu, R.K.; Fields, C.J.; Moise, I.K.; Kim, C.H. Effect of pesticides on microbial communities in container aquatic habitats. Sci. Rep. 2017, 7, 44565. [CrossRef] [PubMed]

29. Bararunyeretse, P.; Ji, H.; Yao, J. Toxicity of nickel to soil microbial community with and without the presence of its mineral collectors-A calorimetric approach. Environ. Sci. Pollut. Res. 2017, 24, 15134-15147. [CrossRef] [PubMed]

30. Piterina, A.V.; Bartlett, J.; Pembroke, J.T. Molecular Analysis of Bacterial Community DNA in Sludge Undergoing Autothermal Thermophilic Aerobic Digestion (ATAD): Pitfalls and Improved Methodology to Enhance Diversity Recovery. Diversity 2010, 2, 505-526. [CrossRef]

31. Hill, G.T.M.; Mitkowski, N.A.; Aldrich-Wolfe, L.; Emele, L.R.; Jurkonie, D.D.; Ficke, A.; Maldonado-Ramirez, S.; Lynch, S.T.; Nelson, E.B. Methods for assessing the composition and diversity of soil microbial communities. Appl. Soil Ecol. 2000, 15, 25-36. [CrossRef]

32. Pichler, M.; Coskun, Ö.K.; Ortega-Arbulú, A.S.; Conci, N.; Wörheide, G.; Vargas, S.; Orsi, W.D. A 16S rRNA gene sequencing and analysis protocol for the Illumina MiniSeq platform. Microbiol. Open 2018, 7, e00611. [CrossRef]

33. Fierer, N.; Schimel, J.P.; Holden, P.A. Variations in microbial community composition through two soil depth profiles. Soil Biol. Biochem. 2003, 35, 167-176. [CrossRef]

34. Ahamadou, B.; Huang, Q.; Chen, W.; Wen, S.; Zhang, J.; Mohamed, I.; Cai, P.; Liang, W. Microcalorimetric assessment of microbial activity in long-term fertilization experimental soils of Southern China. FEMS Microbiol. Ecol. 2009, 70, 186-195. [CrossRef]

35. Chen, H.; Zhuang, R.; Yao, J.; Wang, F.; Qian, Y.; Masakorala, K.; Cai, M.; Liu, H. Short-term effect of aniline on soil microbial activity: A combined study by isothermal microcalorimetry, glucose analysis, and enzyme assay techniques. Environ. Sci. Pollut. Res. Int. 2014, 21, 674-683. [CrossRef]

36. Li, H.; Yao, J.; Gu, J.; Duran, R.; Roha, B.; Jordan, G.; Liu, J.; Min, N.; Lu, C. Microcalorimetry and enzyme activity to determine the effect of nickel and sodium butyl xanthate on soil microbial community. Ecotoxicol. Environ. Saf. 2018, 163, 577-584. [CrossRef] [PubMed]

37. Chen, H.; Yao, J.; Wang, F.; Choi, M.M.; Bramanti, E.; Zaray, G. Study on the toxic effects of diphenol compounds on soil microbial activity by a combination of methods. J. Hazard. Mater. 2009, 167, 846-851. [CrossRef] [PubMed]

38. Critter, S.A.; Freitas, S.S.; Airoldi, C. Comparison between microorganism counting and a calorimetric method applied to tropical soils. Thermochim. Acta 2002, 394, 133-144. [CrossRef]

39. Li, J.; Wu, X.; Gebremikael, M.T.; Wu, H.; Cai, D.; Wang, B.; Li, B.; Zhang, J.; Li, Y.; Xi, J. Response of soil organic carbon fractions, microbial community composition and carbon mineralization to high-input fertilizer practices under an intensive agricultural system. PLoS ONE 2018, 13, e0195144. [CrossRef] [PubMed]

40. Xu, S.; Yao, J.; Ainiwaer, M.; Hong, Y.; Zhang, Y. Analysis of Bacterial Community Structure of Activated Sludge from Wastewater Treatment Plants in Winter. Biomed. Res. Int. 2018, 2018, 8278970. [CrossRef] [PubMed]

41. Li, K.; Dan, Z.; Gesang, L.; Wang, H.; Zhou, Y.; Du, Y.; Ren, Y.; Shi, Y.; Nie, Y. Comparative Analysis of Gut Microbiota of Native Tibetan and Han Populations Living at Different Altitudes. PLoS ONE 2016, 11, e0155863. [CrossRef] [PubMed]

42. Yi, X.; Yuan, J.; Zhu, Y.; Yi, X.; Zhao, Q.; Fang, K.; Cao, L. Comparison of the Abundance and Community Structure of N-Cycling Bacteria in Paddy Rhizosphere Soil under Different Rice Cultivation Patterns. Int. J. Mol. Sci. 2018, 19, 3772. [CrossRef] [PubMed] 
43. Zhang, Q.; Sun, J.; Liu, S.; Wei, Q. Manure refinement affects apple rhizosphere bacterial community structure: A study in sandy soil. PLoS ONE 2013, 8, e76937. [CrossRef]

44. Jiang, J.; Song, Z.; Yang, X.; Mao, Z.; Nie, X.; Guo, H.; Peng, X. Microbial community analysis of apple rhizosphere around Bohai Gulf. Sci. Rep. 2017, 7, 8918. [CrossRef]

45. Edgar, R.C. UPARSE: Highly accurate OTU sequences from microbial amplicon reads. Nat. Methods 2013, 10, 996. [CrossRef]

46. Schloss, P.D.; Westcott, S.L.; Ryabin, T.; Hall, J.R.; Hartmann, M.; Hollister, E.B.; Lesniewski, R.A.; Oakley, B.B.; Parks, D.H.; Robinson, C.J.; et al. Introducing mothur: open-source, platform-independent, community-supported software for describing and comparing microbial communities. Appl. Environ. Microbio. 2009, 75, 7537-7541. [CrossRef] [PubMed]

47. Ashley, S.; Jo, H. Beyond the Venn diagram: The hunt for a core microbiome. Environ. Microbiol. 2012, 14, 4-12.

48. Cole, J.R.; Wang, Q.; Caedenas, E.; Fish, J.; Chai, B.; Farris, R.J.; Kulam-syed-Mohideen, A.S.; McGarrel, D.M.; Marsh, T.; Garrity, G.M.; et al. The Ribosomal Database Project: improved alignments and new tools for rRNA analysis. Nucleic Acids Res. 2009, 37, D141-D145. [CrossRef] [PubMed]

49. Quast, C.; Pruesse, E.; Yilmaz, P.; Gerken, J.; Schweer, T.; Yarza, P.; Peplies, J.; Glöckner, F.O. The SILVA ribosomal RNA gene database project: improved data processing and web-based tools. Nucleic Acids Res. 2013, 41, 590-596. [CrossRef] [PubMed]

50. Święciło, A.; Zych-Wężyk, I. Bacterial stress response as an adaptation to life in a soil environment. Pol. J. Environ. Stud. 2013, 22, 1577.

51. Alboghobeish, H.; Tahmourespour, A.; Doudi, M. The study of Nickel Resistant Bacteria (NiRB) isolated from wastewaters polluted with different industrial sources. J. Environ. Health Sci. Eng. 2014, 12, 44. [CrossRef] [PubMed]

52. Macomber, L.; Hausinger, R.P. Mechanisms of nickel toxicity in microorganisms. Metallomics 2011, 3, 1153-1162. [CrossRef] [PubMed]

53. Denkhaus, E.; Salnikow, K. Nickel essentiality, toxicity, and carcinogenicity. Crit. Rev. Oncol. Hematol. 2002, 42, 35-56. [CrossRef]

54. Khan, A.; Schuler, M.; Prior, M.; Yong, S.; Coppock, R.; Florence, L.; Lillie, L. Effects of hydrogen sulfide exposure on lung mitochondrial respiratory chain enzymes in rats. Toxicol. Appl. Pharmacol. 1990, 103, 482-490. [CrossRef]

55. Gu, Y.; Nostrand, J.D.V.; Wu, L.; He, Z.; Qin, Y.; Zhao, F.J.; Zhou, J. Bacterial community and arsenic functional genes diversity in arsenic contaminated soils from different geographic locations. PLoS ONE 2017, 12, e0176696.

56. Stevens, H.; Stubner, M.; Simon, M.; Brinkhoff, T. Phylogeny of Proteobacteria and Bacteroidetes from oxic habitats of a tidal flat ecosystem. FEMS Microbiol. Ecol. 2005, 54, 351-365. [CrossRef] [PubMed]

57. Spain, A.M.; Krumholz, L.R.; Elshahed, M.S. Abundance, composition, diversity and novelty of soil Proteobacteria. ISME J. 2009, 3, 992. [CrossRef] [PubMed]

58. Gupta, R.S. The phylogeny of proteobacteria: Relationships to other eubacterial phyla and eukaryotes. FEMS Microbiol. Rev. 2000, 24, 367-402. [CrossRef] [PubMed]

59. Peng, M.; Zi, X.; Wang, Q. Bacterial community diversity of oil-contaminated soils assessed by high throughput sequencing of $16 \mathrm{~S}$ rRNA genes. Int. J. Environ. Res. Public Health 2015, 12, 12002-12015. [CrossRef] [PubMed]

60. Parajuli, A.; Grönroos, M.; Kauppi, S.; Płociniczak, T.; Roslund, M.I.; Galitskaya, P.; Laitinen, O.H.; Hyöty, H.; Jumpponen, A.; Strömmer, R. The abundance of health-associated bacteria is altered in PAH polluted soils-Implications for health in urban areas? PLoS ONE 2017, 12, e0187852. [CrossRef] [PubMed]

61. DeBruyn, J.M.; Mead, T.J.; Wilhelm, S.W.; Sayler, G.S. PAH biodegradative genotypes in Lake Erie sediments: Evidence for broad geographical distribution of pyrene-degrading mycobacteria. Environ. Sci. Technol. 2009, 43, 3467-3473. [CrossRef] [PubMed]

62. Chen, S.; Gong, W.; Mei, G.; Zhou, Q.; Bai, C.; Xu, N. Primary biodegradation of sulfide mineral flotation collectors. Miner. Eng. 2011, 24, 953-955. [CrossRef]

63. Hamsavathani, V.; Aysha, O.; Valli, S. Biodegradation of xenobiotics: A review on petroleum hydrocarbons and pesticide degradation. WJ Pharma Pharm. Sci. 2015, 4, 1791-1808. 
64. Dabrowska, D.; Kot-Wasik, A.; Namiesnik, J. The Importance of Degradation in the Fate of Selected Organic Compounds in the Environment. Part II. Photodegradation and Biodegradation. Pol. J. Environ. Stud. 2004, 13.

65. Seo, J.-S.; Keum, Y.-S.; Li, Q. Bacterial degradation of aromatic compounds. Int. J. Environ. Res. Public Health 2009, 6, 278-309. [CrossRef]

66. Das, A.C.; Debnath, A. Effect of systemic herbicides on N2-fixing and phosphate solubilizing microorganisms in relation to availability of nitrogen and phosphorus in paddy soils of West Bengal. Chemosphere 2006, 65, 1082-1086. [CrossRef] [PubMed]

67. Traag, B.A.; Pugliese, A.; Eisen, J.A.; Losick, R. Gene conservation among endospore-forming bacteria reveals additional sporulation genes in Bacillus subtilis. J. Bacteriol. 2013, 195, 253-260. [CrossRef] [PubMed]

68. Valverde, A.; González-Tirante, M.; Medina-Sierra, M.; Santa-Regina, I.; García-Sánchez, A.; Igual, J.M. Diversity and community structure of culturable arsenic-resistant bacteria across a soil arsenic gradient at an abandoned tungsten-tin mining area. Chemosphere 2011, 85, 129-134. [CrossRef] [PubMed]

69. Bento, F.M.; Camargo, F.A.; Okeke, B.C.; Frankenberger, W.T. Comparative bioremediation of soils contaminated with diesel oil by natural attenuation, biostimulation and bioaugmentation. Bioresour. Technol. 2005, 96, 1049-1055. [CrossRef] [PubMed]

70. Burkhardt, E.-M.; Bischoff, S.; Akob, D.M.; Büchel, G.; Küsel, K. Heavy metal tolerance of Fe (III)-reducing microbial communities in contaminated creek bank soils. Appl. Environ. Microbiol. 2011, 77, 3132-3136. [CrossRef]

71. Nicholson, W.L.; Munakata, N.; Horneck, G.; Melosh, H.J.; Setlow, P. Resistance of Bacillus endospores to extreme terrestrial and extraterrestrial environments. Microbiol. Mol. Biol. Rev. 2000, 64, 548-572. [CrossRef]

72. Sharmin, F.; Wakelin, S.; Huygens, F.; Hargreaves, M. Firmicutes dominate the bacterial taxa within sugar-cane processing plants. Sci. Rep. 2013, 3, 3107. [CrossRef]

73. Yuan, M.; Yu, Y.; Li, H.-R.; Dong, N.; Zhang, X.-H. Phylogenetic diversity and biological activity of actinobacteria isolated from the Chukchi Shelf marine sediments in the Arctic Ocean. Mar. Drugs 2014, 12, 1281-1297. [CrossRef]

74. Qiu, M.; Zhang, R.; Xue, C.; Zhang, S.; Li, S.; Zhang, N.; Shen, Q. Application of bio-organic fertilizer can control Fusarium wilt of cucumber plants by regulating microbial community of rhizosphere soil. Biol. Fertil. Soils 2012, 48, 807-816. [CrossRef]

75. Remenár, M.; Harichová, J.; Zámocký, M.; Pangallo, D.; Szemes, T.; Budiš, J.; Soltys, K.; Ferianc, P. Metagenomics of a nickel-resistant bacterial community in an anthropogenic nickel-contaminated soil in southwest Slovakia. Biologia 2017, 72, 971-981. [CrossRef]

76. Hasani, A.; Kariminik, A.; Issazadeh, K. Streptomycetes: Characteristics and their antimicrobial activities. Int. J. Adv. Biol. Biomed. Res. 2014, 2, 63-75.

77. Ceylan, O.; Okmen, G.; Ugur, A. Isolation of soil Streptomyces as source antibiotics active against antibiotic-resistant bacteria. Eurasian J. Biosci. 2008, 2, 73-82.

78. Jorge, V.; Inti, P.; Raquel, Q.; Dodson, R.J.; Herve, T.; Robert, B.; Eisen, J.A.; Holmes, D.S. Acidithiobacillus ferrooxidans metabolism: From genome sequence to industrial applications. BMC Genom. 2008, 9, 597.

79. Seifelnassr, A.A.S.; Abouzeid, A.-Z.M. Exploitation of Bacterial Activities in Mineral Industry and Environmental Preservation: An Overview. J. Min. 2013, 2013, 1-13. [CrossRef]

80. Raja, C.E.; Selvam, G.S.; Omine, K. Isolation, identification and characterization of heavy metal resistant bacteria from sewage. In Proceedings of the International Joint Symp on Geodisaster Prevention and Geoenvironment in Asia, Fukuoka, Japan, 24-25 November 2009; pp. 205-211.

81. Deo, N.; Natarajan, K.A. Biological removal of some flotation collector reagents from aqueous solutions and mineral surfaces. Miner. Eng. 1998, 11, 717-738. [CrossRef]

82. Dong, Y.B.; Lin, H.; Kai-Bin, F.U.; Xiao-Lan, M.O.; Wen, H.W. Effect of flotation reagents on bioleaching of low grade copper tailings by Acidthiobacillus ferrooxidans. Chin. J. Nonferrous Met. 2011, 21, 2291-2297.

83. Okibe, N.; Johnson, D.B. Toxicity of flotation reagents to moderately thermophilic bioleaching microorganisms. Biotechnol. Lett. 2002, 24, 2011-2016. [CrossRef]

84. Bhagat, N.; Vermani, M.; Bajwa, H.S. Characterization of heavy metal (cadmium and nickle) tolerant Gram negative enteric bacteria from polluted Yamuna River, Delhi. Afr. J. Microbiol. Res. 2016, 10, 127-137.

85. Kacar, A. Investigation of Heavy Metal-Resistant Sediment Bacteria and Some Water Quality Parameters: A Case Study of Lake Bafa (Turkey). Int. J. Environ. Res. 2015, 9, 813-822. 
86. Dehghan, R.; Dianati, M. The effects of $\mathrm{Pb}-\mathrm{Zn}$ flotation reagents on the bioleaching process by mesophilic bacteria. Int. J. Miner. Process. 2015, 143, 80-86. [CrossRef]

87. Dedysh, S.N.; Sinninghe Damsté, J.S. Acidobacteria; John Wiley \& Sons Ltd.: Chichester, UK, 2018; pp. 1-10. [CrossRef]

88. Shan, H.; Chen, C.; Jaffé, P.R. Seasonal distribution of nitrifiers and denitrifiers in urban river sediments affected by agricultural activities. Sci. Total Environ. 2018, 642, 1282-1291.

89. Shan, H.; Chen, C.; Peng, X.; Jaffé, P.R. Environmental factors affecting the presence of Acidimicrobiaceae and ammonium removal under iron-reducing conditions in soil environments. Soil Biol. Biochem. 2016, 98, 148-158.

(C) 2019 by the authors. Licensee MDPI, Basel, Switzerland. This article is an open access article distributed under the terms and conditions of the Creative Commons Attribution (CC BY) license (http://creativecommons.org/licenses/by/4.0/). 